\title{
Quantifying the Impact of Parametric Uncertainty on Automatic Mechanism Generation for $\mathrm{CO}_{2}$ Hydrogenation on $\mathrm{Ni}(111)$
}

\author{
Bjarne Kreitz,* Khachik Sargsyan, Katrín Blöndal, Emily J. Mazeau, Richard H. West, \\ Gregor D. Wehinger, Thomas Turek, and C. Franklin Goldsmith*
}

Cite This: JACS Au 2021, 1, 1656-1673

Read Online

\section{ACCESS |}

Џlll Metrics \& More

Article Recommendations

Supporting Information

ABSTRACT: Automatic mechanism generation is used to determine mechanisms for the $\mathrm{CO}_{2}$ hydrogenation on $\mathrm{Ni}(111)$ in a two-stage process while considering the correlated uncertainty in DFT-based energetic parameters systematically. In a coarse stage, all the possible chemistry is explored with gas-phase products down to the ppb level, while a refined stage discovers the core methanation submechanism. Five thousand unique mechanisms were generated, which contain minor perturbations in all parameters. Global uncertainty assessment, global sensitivity analysis, and degree of rate control analysis are performed to study the effect of this parametric uncertainty on the microkinetic model predictions. Comparison of the model predictions with experimental data on a $\mathrm{Ni} / \mathrm{SiO}_{2}$ catalyst find a feasible set of microkinetic mechanisms within the correlated uncertainty space that are in quantitative agreement with the measured data, without relying on explicit parameter optimization. Global uncertainty and sensitivity analyses provide tools to determine the pathways and key factors that control the methanation activity within the parameter space. Together, these methods reveal that the degree of rate control approach can be misleading if parametric uncertainty is not considered. The procedure of considering uncertainties in the automated mechanism generation is not unique to $\mathrm{CO}_{2}$ methanation and can be easily extended to other challenging heterogeneously catalyzed reactions.

KEYWORDS: rate-based algorithm, RMG, methanation, carbon dioxide, global uncertainty analysis

\section{INTRODUCTION}

Methanation is a promising technology for reducing $\mathrm{CO}_{2}$ emissions while producing sustainable natural gas. From a climate-change perspective, the process is particularly advantageous when excess renewable energy is used to generate the requisite $\mathrm{H}_{2}$ via water splitting as part of the power-to-gas process. ${ }^{1,2}$ However, volatility in renewable energy sources induces challenges on the transient operation of a catalytic reactor. ${ }^{3}$ Given that the net reaction, $\mathrm{CO}_{2}+4 \mathrm{H}_{2} \rightleftharpoons \mathrm{CH}_{4}+2$ $\mathrm{H}_{2} \mathrm{O}$, is exothermic, $\Delta H_{\mathrm{rxn}}(298 \mathrm{~K})=-164.7 \mathrm{~kJ} \mathrm{~mol}^{-1}$, transient operation can lead to undesirable temperature and concentration gradients. ${ }^{4-6}$ Accordingly, an accurate microkinetic mechanism is essential for optimizing reactor performance.

The most commonly used methanation catalyst is $\mathrm{Ni}$, due to its good performance at reasonable costs. ${ }^{2,7} \mathrm{Ni}(111)$ has the highest share on a $\mathrm{Ni}$ crystal, ${ }^{8}$ yet its role in $\mathrm{CO}_{2}$ methanation is unresolved, despite extensive research. ${ }^{9-17}$ Experiments with $\mathrm{Ni} / \gamma-\mathrm{Al}_{2} \mathrm{O}_{3}$ catalysts point to the higher activity of $\mathrm{Ni}(111)$ terrace sites, whereas experiments on $\mathrm{Ni} / \mathrm{SiO}_{2}$ show a higher activity of $\mathrm{Ni}(211)$ steps, which are also considered to be the active site for $\mathrm{CO}$ methanation. ${ }^{18}$ Lozano-Reis et al. ${ }^{12}$ combined density functional theory (DFT) calculations using the BEEF-vdW functional and kinetic Monte Carlo simulations to demonstrate that the $\mathrm{Ni}(111)$ surface is inactive for the $\mathrm{CO}_{2}$ methanation; instead, they argued that the catalyst converts the $\mathrm{CO}_{2}$ to $\mathrm{CO}$ in the reverse water-gas shift (RWGS) reaction, $\mathrm{CO}_{2}+\mathrm{H}_{2} \rightleftharpoons \mathrm{CO}+\mathrm{H}_{2} \mathrm{O}$, with the $\mathrm{CO}_{2}$ * dissociation being the rate-determining step (RDS). Vogt et al. ${ }^{10}$ investigated the four most important Ni facets by DFT with the PBE functional. They showed in a mean-field microkinetic model that although the $\mathrm{Ni}(111)$ facet is not as active as the open (110) facet, it still exhibited some methanation activity. These authors identified the dissociation of $\mathrm{HCO}^{*}$ as the RDS, which is supported by Zhou et al. ${ }^{15}$ from DFT calculations with the same functional. In addition to these models of $\mathrm{CO}_{2}$ hydrogenation on $\mathrm{Ni}(111)$, other studies focused on the (reverse) water-gas shift reaction, ${ }^{19-21}$ methanol synthesis, ${ }^{22}$ and formic acid formation. ${ }^{23}$ Apart from the general role/activity of the $\mathrm{Ni}(111)$ facet, the dominant reaction network for $\mathrm{CO}_{2}$ hydrogenation has not

Received: June 18, 2021

Published: August 16, 2021 
been conclusively determined; the aforementioned computational studies disagree about important intermediates, pathways, and the RDS.

The microkinetic mechanism for $\mathrm{CO}_{2}$ hydrogenation on $\mathrm{Ni}(111)$ can be developed based on surface science experiments assisted by operando methods, ${ }^{9,10,13,24,25}$ computational methods (e.g., DFT), ${ }^{16,19,26-29}$ or better a combination of both. $^{30-32}$ DFT-based microkinetic mechanisms are increasingly common due to the availability of "black-box" electronic structure codes. Although modern DFT functionals are reliable for adsorbate thermochemistry and kinetics, these calculations remain computationally expensive. Accordingly, given a "computational budget", researchers must prioritize which intermediates and transition states to investigate. This process assumes that the researcher knows a priori which intermediates and transition states will be important. Consequently, the mechanism generation process can be biased by the developer's expectations. ${ }^{3,34}$ An alternative to DFT-based mechanism development is to use approximate methods that, while less accurate, are orders of magnitude faster. One such method is applying linear scaling (LS) relations, which are based on the d-band model. ${ }^{35}$ LS relations can accelerate the procedure $^{36}$ and are often used for catalyst screening. ${ }^{28,29,37,38}$ Although these approximate methods save computational resources, they still require expertise and intuition to develop the mechanism, and this procedure does not avoid the problem of incompleteness due to bias. An alternative to constructing mechanisms "by hand" is to use computers to propose and evaluate possible elementary reactions. ${ }^{39-46}$ One such approach is the automatic Reaction Mechanism Generator (RMG) of Green and co-workers. ${ }^{43,47,48}$ Originally developed for gas-phase pyrolysis, RMG has been expanded to include reactions on surfaces. ${ }^{4-47}$

The omission (intentional or unintentional) of certain reactions can be characterized as mechanistic or structural uncertainty. ${ }^{49}$ In addition to bias, a second problem with microkinetic mechanism generation is parametric uncertainty. All of the DFT-derived parameters carry uncertainties because of the assumptions made in the exchange-correlation functional. Consequently, the DFT-derived binding energies have an uncertainty of $\pm 0.3 \mathrm{eV}^{32,50-54}$ These uncertainties in binding energies for different adsorbates are correlated ${ }^{34,51-53}$ (indeed, some degree of correlation is implicit in $\mathrm{LS}^{35}$ ). The correlation of the uncertainties can be distorted due to systematic uncertainties introduced by the specific DFT functional, e.g., overbinding of covalent bonds and inaccurate quantification of dispersion interactions in the PBE functional. ${ }^{55}$ In addition to correlation among adsorbate thermochemistry, reaction kinetics are correlated as well, as exemplified by Brønsted-Evans-Polanyi (BEP) relations. ${ }^{56}$ The uncertainty in model parameters should be propagated to the outputs of the model, e.g., conversion, turnover frequency (TOF), ${ }^{50-52,57,58}$ and the identification of the most likely product formation pathways within a mechanism. ${ }^{51,59,60}$ However, given the large uncertainty in model parameters, some pathways or intermediates might have been overlooked when creating the mechanism by hand because of the highly complex landscape of the potential energy surface. ${ }^{34,53}$ Therefore, it is necessary to account for the uncertainty directly in the mechanism generation procedure to provide an exhaustive analysis of all possible reactions and intermediates.

The present work aims to combine experiment, theory, and modeling to develop a microkinetic model for the hydro- genation of $\mathrm{CO}_{2}$ on $\mathrm{Ni}(111)$. Instead of propagating uncertainty from a final microkinetic model to the simulation outputs, we take a novel approach and include the uncertainty directly in the mechanism generation procedure in RMG and propagate the uncertainty to the predicted mechanism. The automatic mechanism generation process is repeated 5,000 times, with each new mechanism including small perturbations in the DFT-derived parameters that can also result in mechanisms with different species and reactions. Therefore, we can discover all possible reactions and intermediates in a vast reaction network. Global sensitivity analysis (GSA) and local sensitivity analysis using the degree of rate control (DRC) $)^{61,62}$ are used to identify the most important species and reactions over the whole uncertainty range. The mechanisms are compared against experimental data for a $\mathrm{Ni} / \mathrm{SiO}_{2}$ catalyst in a differential fixed-bed reactor. This comparison determines a feasible set of microkinetic mechanisms in the uncertainty range that quantitatively agree with the experimental data. Combining all of the methods allows us to advance our understanding of the most important pathways for methane formation and the factors that govern the methanation activity on $\mathrm{Ni}(111)$. Further, applying the DRC on each unique mechanism shows how versatile the DRC can be in the uncertainty range of current DFT functionals and how much more information on the controlling factors is obtained when global uncertainty is considered. This study provides an example of the benefit of automated mechanism generation and the consideration of uncertainties to discover all the possible chemistry.

\section{MATERIALS AND METHODS}

\section{Microkinetic Mechanism Generation}

Automated mechanism generation was performed with RMG (version $3.0) .{ }^{47,48}$ A detailed explanation of the RMG software can be found in the work of Gao et al. ${ }^{43}$ and the extension to heterogeneously catalyzed reactions in the publication from Goldsmith and West. ${ }^{44}$ Only a brief explanation of the key features important for this work is provided. Elementary reactions are grouped according to reaction families, which are templates that convert the chemical graphs of reactants into products. RMG must provide thermodynamic properties and kinetics for each proposed adsorbate and elementary reaction, respectively. RMG combines a database of precompiled values, but it can supplement these databases with rules for predicting the properties of novel species/reactions. The total species population is divided into two groups: core and edge. Core species are essential to the mechanism, and only the reactants are contained in the core at the start of the process. The species in the core are iterated through the reaction families, which potentially will generate new species. RMG uses a rate-based algorithm to expand the mechanism. ${ }^{43,63}$ When RMG proposes a new species, that species starts off in the edge. If the net production rate of that edge species is sufficiently large (based upon user-defined criteria), it is moved from the edge to the core, and the process begins anew. Thus, RMG exhaustively considers all possible reactions that are consistent with the various reaction families for the core species; however, it only retains the species that are kinetically relevant for the conditions of interest.

Thermodynamic properties of the adsorbates on the Ni facet were estimated via LS relations $^{35}$ (see eq 1), which were recently implemented in RMG by Mazeau et al., ${ }^{45}$ based on reference values for $\mathrm{Pt}(111)$ obtained via $\mathrm{BEEF}-\mathrm{vdW}$ calculations in ref 46 . The binding energy of an adsorbate is estimated via

$$
\Delta E_{\mathrm{Ni}}^{\mathrm{AX}}=\Delta E_{\mathrm{Pt}}^{\mathrm{AX}}+\gamma\left(\Delta E_{\mathrm{Ni}}^{\mathrm{A}}-\Delta E_{\mathrm{Pt}}^{\mathrm{A}}\right)
$$

where $\Delta E_{\mathrm{Pt}}^{\mathrm{AX}}$ is the binding energy of the adsorbate $\mathrm{AX}^{*}$ in the $\mathrm{Pt}(111)$ database, where $\mathrm{X}$ represents any adsorbate that binds 
through $\mathrm{A}^{*}, \Delta E_{\mathrm{Ni}}^{\mathrm{A}}$ is the binding energy of the adatom $\mathrm{A}^{*}, \Delta E_{\mathrm{Pt}}^{\mathrm{A}}$ is the analogous property for $\operatorname{Pt}(111)$, and the slope $\gamma$ is related to the degree of saturation for the adsorbate. Accordingly, RMG requires values for $\Delta E_{\mathrm{Ni}}^{\mathrm{H}}, \Delta E_{\mathrm{Ni}}^{\mathrm{C}}$, and $\Delta E_{\mathrm{Ni}}^{\mathrm{O}}$ for the $\mathrm{Ni}(111)$ facet for use in the LS procedure. These values were obtained from DFT calculations. ${ }^{8}$ Additionally, the $\mathrm{Pt}(111)$ database in ref 46 only considered adsorbates with no more than two heavy atoms (C, N, and O); RMG can use those values to estimate the thermodynamic properties of larger adsorbates. ${ }^{64}$ However, we anticipated that three adsorbates- $\mathrm{CO}_{2} *, \mathrm{HCOO} *$, and $\mathrm{COOH}^{*}$-would be essential to the model, and so new DFT values were added to the $\operatorname{Pt}(111)$ database. DFT calculations were performed using the $\mathrm{RPBE}^{65}$ functional in $\operatorname{VASP}^{66,67}$ with dispersion correction ${ }^{68}$ and converted to thermodynamic properties of the adsorbates, as described in ref 46. A detailed description of the DFT method is provided in the Supporting Information (SI).

As mentioned above, elementary reactions are provided in the form of templates for a certain reaction family. Kinetic parameters typically are provided as an Arrhenius fit, $k(T)=A \exp \left(-E_{\mathrm{a}} / R T\right)$, where $A$ is the pre-exponential factor, $E_{\mathrm{a}}$ is the activation energy, and $R$ is the ideal gas constant. RMG estimates only kinetic parameters in the forward direction; the reverse rate constant is computed from the equilibrium constant, which ensures thermodynamic consistency. In the present study, we assumed that $\mathrm{CO}_{2}$ and $\mathrm{H}_{2} \mathrm{O}$ adsorb associatively. ${ }^{9,12,20} \mathrm{CH}_{4}$, in contrast, has two possible adsorption pathways: association to a physisorbed precursor state $\mathrm{CH}_{4}{ }^{*}$ (which can then go on to dissociate on the surface $)^{69,70}$ and direct dissociative adsorption to $\mathrm{CH}_{3} *$ and $\mathrm{H}^{*}$., ${ }^{9}, 12$

RMG includes several libraries of rate constants, which have been taken from values reported in the literature or computed via DFT. ${ }^{47}$ However, for the purpose of the present work, all of the rate constants were estimated using BEP relations, with one exception, the dissociation of $\mathrm{CO}_{2}{ }^{*}$. Due to the comparatively unique structure of $\mathrm{CO}_{2}{ }^{*}$, the activation energy for $\mathrm{CO}_{2}{ }^{*}$ dissociation is not well described by the general BEP relation for cleavage a $\mathrm{C}=\mathrm{O}$ bond on a surface and was, therefore, included as a specific reaction in a library based on previous work. ${ }^{8}$ By eliminating the reaction libraries in favor of the BEP relations, we can systematically quantify the effects of correlated uncertainty in thermodynamic properties (e.g., heats of formation) on rate constants and vary all reactions within a given reaction family. ${ }^{56,71}$ Accordingly, the activation energy for surface reactions is estimated using a $\mathrm{BEP}$ relation specific for that reaction family

$$
E_{\mathrm{a}}=E_{\mathrm{a}}^{0}+\alpha \Delta H_{\mathrm{rxn}}
$$

where the intercept $E_{\mathrm{a}}{ }^{0}$ is the characteristic activation energy of a reaction family and $\alpha$ is the dimensionless slope of the BEP, so that the activation energy scales with the heat of reaction, $\Delta H_{\mathrm{rxn}}$. BEP relations are organized in a tree structure with the most general relation at the top (e.g., generic bond fission) and more specific child nodes beneath (e.g., C-C bond fission). RMG climbs down the tree to the most specific node available to estimate kinetic parameters.

The present work builds upon the pre-existing reaction families for surface kinetics, ${ }^{44,45}$ which can be categorized into adsorption/ desorption, bond fission, and abstraction. All of the existing BEP values were updated based upon new DFT calculations or literature data. In particular, new values were added for the abstraction families (see the SI for details). The overwhelming majority of microkinetic mechanisms consist of only adsorption/desorption and bond fission reactions; the inclusion of bimolecular-to-bimolecular reactions, such as abstraction, have been primarily neglected ${ }^{33,34}$ but can become important, especially at high coverage conditions. ${ }^{72}$ As will be demonstrated in the Results, these abstraction reactions can contribute significantly to the overall reactivity of the system. The rate constants were computing using transition state theory, with the saddle points obtained via the climbing-image nudged elastic band (CINEB) method $^{73}$ (see the SI for further details). A complete summary of the reaction families, including the BEP relations used for the mechanism generation procedure, is provided in Table S1 and
Figures $\mathrm{S} 1-\mathrm{S} 10$. The initial conditions of the mechanism generation process were set to a stoichiometric $\mathrm{H}_{2} / \mathrm{CO}_{2}$ mixture, with a vacant $\mathrm{Ni}(111)$ surface, at temperatures of 573 and $673 \mathrm{~K}$, and a pressure of 1 bar. Further parameters and settings used for the generation procedure are summarized in Table S2.

\section{Experiments}

$\mathrm{CO}_{2}$ methanation experiments were conducted with a $20 \mathrm{wt} \% \mathrm{Ni} /$ $\mathrm{SiO}_{2}$ catalyst produced with a spray-drying method as described in the work of Kreitz et al. ${ }^{74}$ A solution of colloidal $\mathrm{SiO}_{2}$ nanoparticles with a primary particle size of $8 \mathrm{~nm}$ and $\mathrm{Ni}\left(\mathrm{NO}_{3}\right)_{2}$ was sprayed into a tubular furnace operated at $673 \mathrm{~K}$ using an atomizer to initiate a onestep calcination and assembly of $\mathrm{Ni} / \mathrm{SiO}_{2}$ nanoparticles. These nanoparticles were collected on a filter and heat-treated at $673 \mathrm{~K}$ for 3 h. The experiments were conducted with a $\mathrm{Ni} / \mathrm{SiO}_{2}$ catalyst because the acidic surface of the silica does not adsorb $\mathrm{CO}_{2}^{8}$ and, therefore, does not participate in the methanation mechanism. Supports with basic surface sites, in contrast, such as $\gamma-\mathrm{Al}_{2} \mathrm{O}_{3}$ or $\mathrm{CeO}_{2}$, can participate in the mechanism and alter pathways. ${ }^{16,17,75} \mathrm{CO}_{2}$ methanation experiments were performed in a catalyst testing unit with a differential fixed-bed setup at ambient pressure with a stoichiometric $\mathrm{H}_{2} / \mathrm{CO}_{2}$ mixture diluted in $75 \% \mathrm{Ar}$ at a weight hourly space velocity (WHSV) of $100 \mathrm{~L}_{\mathrm{N}} \mathrm{h}^{-1} \mathrm{~g}^{-1}$. A catalyst amount of 30 $\mathrm{mg}$ was used, which results in a length of the catalyst bed of $4 \mathrm{~mm}$. The mixture was purified to remove oxygen and water contaminants. Ar was employed as an internal standard and to reduce thermal effects. A temperature-scanning experiment as described in Kreitz et al. ${ }^{74}$ was used to investigate the methanation reaction over the entire temperature range up to $773 \mathrm{~K}$. During the temperature scan, the temperature was linearly raised with a rate of $20 \mathrm{~K} \mathrm{~min}^{-1}$ (see Table S3 for a summary). The product mole fraction was analyzed with a high temporal resolution using a mass spectrometer. Based on the measured exit gas concentration and using $\mathrm{Ar}$ as an internal standard, the $\mathrm{CO}_{2}$ conversion, $\mathrm{CH}_{4}$ and $\mathrm{CO}$ selectivity, as well as $\mathrm{CH}_{4}$ yield were calculated. Reaction rates, turnover frequencies, and activation energy were calculated for a conversion below $20 \%$ assuming differential fixed-bed conditions. The catalyst was characterized with transmission electron microscopy, $\mathrm{X}$-ray diffraction, $\mathrm{N}_{2}$ physisorption, $\mathrm{H}_{2}$ and $\mathrm{CO}_{2}$ chemisorption, and temperature-programmed desorption. Further details on the catalyst production, catalyst characterization, the experimental setup, and evaluation can be found in refs 8 and 76 and are omitted here for brevity.

\section{Microkinetic Modeling}

The experimental apparatus was modeled as a plug-flow reactor (PFR) using Cantera, ${ }^{77}$ which is an open-source suite of tools for problems involving chemical kinetics, thermodynamics, and transport processes. The PFR was modeled as a series of 100 continuously stirred tank reactors (CSTRs); the number of tanks was tested for convergence. A mean-field microkinetic model was assumed for the $\mathrm{Ni}(111)$ facet. All reactions were treated as reversible. Reaction kinetics were implemented in the forward direction, and the reverse rate constant was always calculated from the equilibrium constant, which ensures thermodynamic consistency. The temperaturescanning experiment was modeled by computing steady-state solutions at several temperature increments. This assumption is justified since no deviation between steady-state and transient results was observed in the experiments. ${ }^{74}$ The parameters for the simulation are summarized in Table S3. As a simplification, no lateral interactions among the adsorbates were considered in the surface mechanism. The Python source code is available in ref 78 .

\section{Parametric Uncertainty in Mechanism Generation}

Global uncertainty analysis (GUA) was recently added to RMG as a postprocessing tool exclusively for gas-phase mechanisms. ${ }^{79}$ The effect of parametric uncertainty on the automatic mechanism generation process itself, in contrast, has not been previously investigated. A major component of the current work is to quantify how uncertainties in the model-generation parameters (e.g., heats of formation, activation energies) can influence the generated mechanism and the final model predictions. The heats of formation for the 
gas-phase species were taken from the Active Thermochemical Tables $^{80,81}$ and are known to within $\pm 0.001 \mathrm{eV}$; consequently, we assume these values to be "exact" and do not consider the impact of their uncertainty further.

For adsorbates, we assume that the binding energies (and thence heats of formation) are accurate to within $\pm 0.3 \mathrm{eV}$, in accordance with the DFT uncertainty. ${ }^{50,51,82}$ As a simplification, we do not consider uncertainty in entropy, which is present as well. ${ }^{32,54}$ Although the uncertainty in the heats of formation is $\pm 0.3 \mathrm{eV}$, there is also a strong correlation in the uncertainty between the adsorbates. ${ }^{52,53,57}$ This correlation has led to the development of the LS concept ${ }^{35}$ (see eq 1) and the breakdown of the correlated adsorbate thermochemistry space to the descriptor species $\mathrm{C}^{*}, \mathrm{H}^{*}$, and $\mathrm{O}^{*}$. Similarly, we can break down the entire uncertainty in the adsorbate thermochemistry to the three LS descriptors as well. The binding energies for $\mathrm{C}^{*}$ and $\mathrm{O}^{*}$ are uncorrelated, as are the binding energies for $\mathrm{O}^{*}$ and $\mathrm{H}^{*}$. However, a modest correlation exists between $\mathrm{C}^{*}$ and $\mathrm{H}^{*}$ (see Figure S12), which can be exploited to further reduce the thermochemistry space to two descriptors. ${ }^{28,83,84}$ The probability density function of the binding energy of these three descriptor species can be constructed with the BEEF-vdW functional. ${ }^{52,57,85}$ As an approximation, we assumed a uniformly distributed uncertainty space and no correlation between the descriptor species in the narrow uncertainty range within this work (see SI for further discussion and demonstration of lack of correlation between $\Delta E_{\mathrm{Ni}}^{\mathrm{H}}, \Delta E_{\mathrm{Ni}}^{\mathrm{C}}$, and $\Delta E_{\mathrm{Ni}}^{\mathrm{O}}$ ). In this work, we exploit the LS concept to propagate the uncertainty in the descriptor species to the uncertainty in the heat of formation of all adsorbates. To ensure the LS concept, we assume that all adsorbates that bind to the surface through the same element $(\mathrm{C}, \mathrm{H}, \mathrm{O})$ should be perturbed in the same direction. This was achieved by perturbing all adsorbate reference binding energies $\Delta E_{\mathrm{Pt}}^{\mathrm{AX}}$ (and thence heats of formation) in the RMG thermochemistry library by $\delta E_{\mathrm{Pt}}^{\mathrm{AX}}$ for all adsorbates that bind through one of the descriptor species (see the SI for an explanation). Thus, the perturbed binding energies are given by

$$
\Delta E_{\mathrm{Ni}}^{\mathrm{AX}}=\left(\Delta E_{\mathrm{Pt}}^{\mathrm{AX}}+\delta E_{\mathrm{Pt}}^{\mathrm{AX}}\right)+\gamma\left(\Delta E_{\mathrm{Ni}}^{\mathrm{A}}-\Delta E_{\mathrm{Pt}}^{\mathrm{A}}\right)
$$

Accordingly, we have three perturbation parameters- $\delta E_{\mathrm{Pt}}^{\mathrm{HX}}, \delta E_{\mathrm{Pt}}^{\mathrm{CX}}$, and $\delta E_{\mathrm{Pt}}^{\mathrm{OX}}$ - that adjust the heats of formation of the adsorbates in the uncertainty space. Additionally, physisorbed species (such as $\mathrm{CH}_{4}{ }^{*}$, $\mathrm{CO}_{2}{ }^{*}$, and $\mathrm{H}_{2} \mathrm{O}^{*}$ ) are not assumed to bind through a particular element and thus are not subjected to the same LS relations. Rather than treat each physisorbed species individually, we simply assume that the well depths for all physisorbed species are correlated, which depends on the DFT functional and the dispersion correction; ${ }^{55}$ this approximation provides the fourth global parameter for adsorbate heats of formation, $\delta E_{\mathrm{Pt}}^{\text {phys }}$. The range of possible values for $\delta E_{\mathrm{Pt}}^{\mathrm{HX}}, \delta E_{\mathrm{Pt}}^{\mathrm{CX}}$, and $\delta E_{\mathrm{Pt}}^{\mathrm{OX}}$ is $\pm 0.3 \mathrm{eV}$; the range for $\delta E_{\mathrm{pt}}^{\text {phs }}$ is $\pm 0.2 \mathrm{eV}$. Admittedly, this approach does not completely describe the true uncertainty (correlated and uncorrelated) in the heats of formation for adsorbates; nonetheless, it does capture how systematic errors in DFT-derived energies can be represented in model generation. A more detailed approach could consider a nonuniformly distributed uncertainty space according to the BEEF-vdW functional. ${ }^{52,57,85}$ This approach is illustrated for $\mathrm{CH}^{*}, \mathrm{OH}^{*}$, and $\mathrm{CO}^{*}$ in the Supporting Information. As can be seen in Figure S12, our assumption of linear scaling is consistent with the $\mathrm{BEEF}-\mathrm{vdW}$ ensemble error estimation; moreover, our uncertainty estimates of $\pm 0.3 \mathrm{eV}$ are in fact quite conservative. Still, as will be demonstrated below, this simplified approach already reveals considerable information about the mechanistic response to correlated parametric uncertainty.

Estimating the correlated uncertainty in the activation energy is an additional challenge. Activation energies within a certain reaction family (e.g., breaking of $\mathrm{C}-\mathrm{H}$ bonds) are correlated via the relation between adsorbate thermochemistry and the activation energy, as is captured by the BEP relation. ${ }^{56,71}$ The uncertainties for activation energies should be larger than for binding energies. The BEP parameters $E_{a}^{0}$ and $\alpha$ are obtained from linear regression (typically to barrier heights obtained from DFT); accordingly, these parameters should be correlated. ${ }^{86}$ However, information on the covariance matrix is seldom available in the literature. Therefore, we did not assume a correlation between $\alpha$ and $E_{a}^{0}$. Instead, we assume that both the intercept and the slope are uncertain, and that the final activation energy is given by

$$
E_{\mathrm{a}}=E_{\mathrm{a}}^{0}+\delta E_{\mathrm{a}}^{0}+(\alpha+\delta \alpha) \Delta H_{\mathrm{rxn}}
$$

To be consistent with the uncertainty in DFT-derived binding energies, the characteristic activation energy (intercept) is perturbed by $\delta E_{\mathrm{a}}^{0}= \pm 0.3 \mathrm{eV}$. The slope is perturbed by $\delta \alpha= \pm 0.15$; this perturbation is conservative compared to uncertainties reported in the literature. ${ }^{72,87}$ Furthermore, the activation energy will be perturbed via changes to the binding energies of the reactants and products via Equation 3, which will change $\Delta H_{\mathrm{rxn}}$. Consequently, the total allowable change in the activation energy is larger than that of the binding energy and can vary significantly within a reaction family. As a simplifying assumption, the pre-exponential factor $A$ was not adjusted. This restriction is rather crude, since pre-exponential factors can vary by an order of magnitude, ${ }^{82}$ but for the temperature range of interest, the uncertainties in the activation energy will have a more significant impact on the overall kinetics. Lastly, we do not assume any correlation among the reaction families. Accordingly, the total number of perturbed parameters is 65: 4 parameters for adsorbate heats of formation, 1 parameter for the activation energy of $\mathrm{CO}_{2}^{*}$ dissociation, and $30 \mathrm{BEP}$ relations (each with 2 parameters). Overall, the approach outlined in this work for the quantification of the correlated uncertainties can be considered consistent with DFT calculations and catalyst screening studies exploiting the correlation of DFTderived binding and activation energies.

The next step is to evaluate how perturbations to these 65 parameters within their stated uncertainty bounds affect the size, complexity, and reactivity of the resulting mechanism. This task was accomplished in two stages. In the first stage, RMG was set to build exhaustive mechanisms by using smaller (tighter) convergence criteria (see Table S2). For this stage, a total of 500 distinct mechanisms were generated by employing a quasi-random sampling of the 65 parameters within the uncertainty range. Quasi-random numbers were generated with the low discrepancy Sobol sequence ${ }^{88}$ using the SobolEngine from PyTorch. ${ }^{89}$ As will be detailed below, these tighter criteria resulted in relatively large mechanisms, including the production of gas-phase products in the $\mathrm{ppb}$ range. This set of mechanisms are referred to as "coarse".

In the second stage, the mechanism generation parameters were adjusted to build smaller mechanisms that focused more on the essential methanation kinetics; the convergence criteria were relaxed (loosened), and a maximum number of carbon atoms of 3 was imposed (see Table $S 2$ for complete values). For this stage, a new Sobol matrix of $65 \times 5,000$ was generated, which resulted in a total of 5,000 unique mechanisms. This set of mechanisms are referred to as "fine". This dense sampling of the parameter space in the fine set will facilitate a global sensitivity analysis (GSA), described below.

\section{Sensitivity Analysis}

Global sensitivity analysis was performed to determine the parameters that contribute the most to the uncertainty of the output while considering the correlation among the input parameters. ${ }^{90}$ The GSA was carried out with the UQTk package. ${ }^{11,92}$ Polynomial chaos expansions (PCE) were used to build a surrogate model based on the 5,000 distinct mechanisms and the corresponding simulation results. PCEs allow analytical extraction of GSA indices via variance decomposition. $.^{93} 4,500$ model results were used to build the surrogate model with third order polynomials, and 500 model results were used for the validation of the model. Total and joint sensitivity indices were determined, measuring output variance contributions one or two parameter at a time, respectively.

The sensitivity indices quantify the contribution of the 65 parameters (LS and BEP parameters) to the observable (model) output variance. Therefore, the GSA in our study provides information only on the reaction families and descriptor species but not on on the importance of a single species or single reaction. A local 

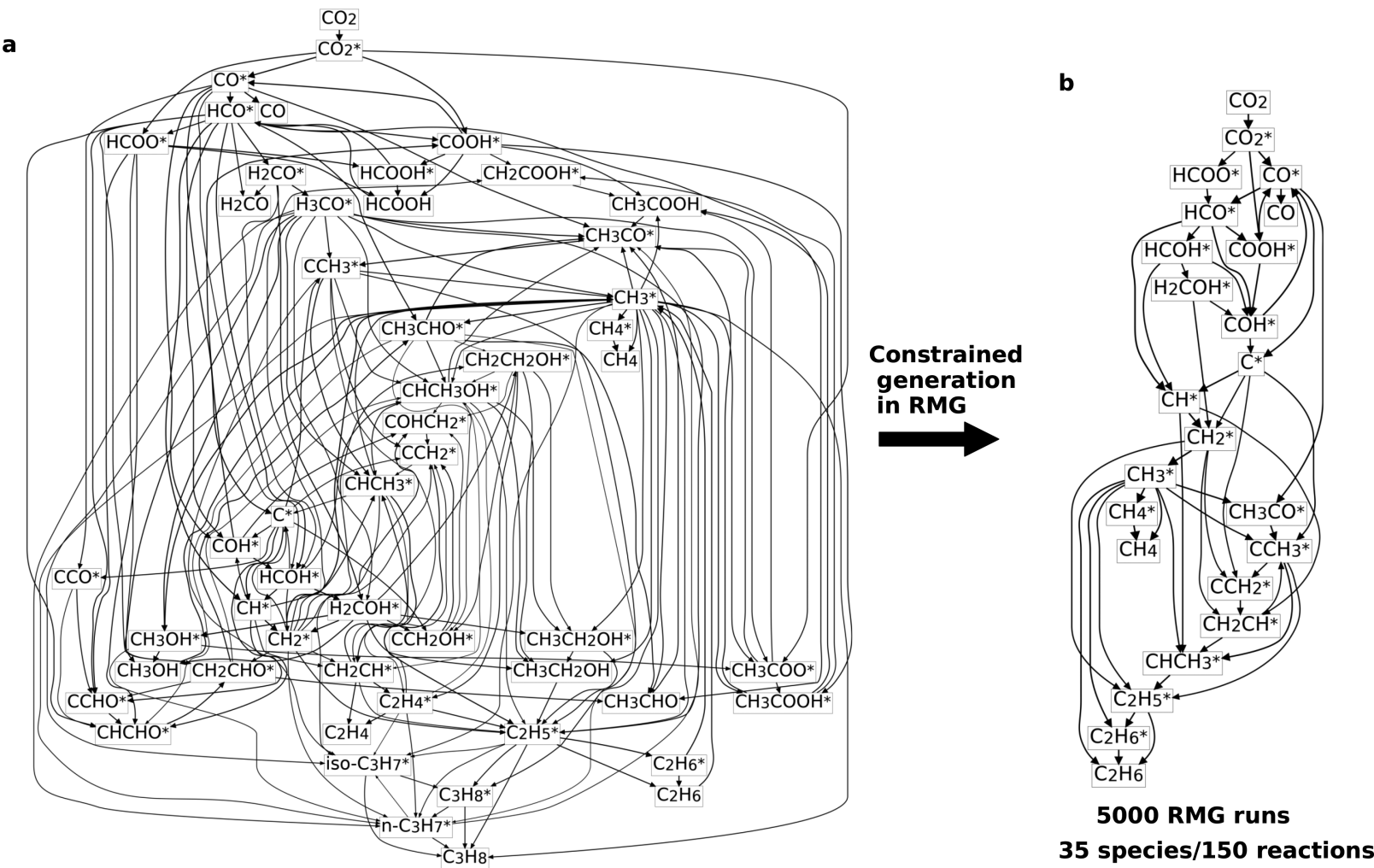

500 RMG runs

Core: 64 species/450 reactions

Edge: 426 species/1205 reactions

Figure 1. (a) Full reaction network of the core mechanism for the hydrogenation of $\mathrm{CO}_{2}$ on $\mathrm{Ni}(111)$ obtained from coarse generation settings. (b) Constrained reaction network from the fine mechanism generation process.

sensitivity analysis was performed to quantify the importance of individual species and reactions. ${ }^{94}$ The mechanisms were evaluated with sensitivity analysis in a steady-state CSTR using the degree of rate control (DRC) ${ }^{61,62,95}$ with respect to the methane formation rate, $r_{\mathrm{CH}_{4}}$, by

$$
X_{\mathrm{RC}}=\frac{k_{i}}{r_{\mathrm{CH}_{4}}}\left(\frac{\partial r_{\mathrm{CH}_{4}}}{\partial k_{i}}\right)
$$

where $k_{i}$ is the forward rate constant of the elementary reaction $i$. In a brute-force (one-at-a-time) method, both forward and reverse rate constant were perturbed by $1 \%$ for each reaction to maintain thermodynamic consistency. Additional DRC analysis was performed with respect to the stability (thermochemistry) of the adsorbates. The intermediates were stabilized by decreasing the standard state Gibbs free energy of formation $\Delta_{\mathrm{f}} G$ by $0.001 \mathrm{eV}$. The degree of thermodynamic rate control of the intermediates $X_{\mathrm{TRC}}{ }^{62,95}$ is given by

$$
X_{\mathrm{TRC}}=\frac{1}{r_{\mathrm{CH}_{4}}}\left(\frac{\partial r_{\mathrm{CH}_{4}}}{\partial\left(\frac{-\Delta_{\mathrm{f}} G}{R T}\right)}\right)
$$

It was ensured that the free energy of all transition states remain unchanged. ${ }^{62,95}$ The perturbations (1\% for rate constants, $0.001 \mathrm{eV}$ for adsorbates) are assumed to be sufficiently small so that the local approximation is valid and that they are not correlated. The DRC for one mechanism has only limited meaning, given the broad range of parametric uncertainty assumed in the mechanism generation process. Accordingly, we performed the DRC analysis in Equation 5 and Equation 6 for all 5,000 mechanisms in the fine data set. As will be demonstrated below, this comprehensive DRC approach, which covers all possible combinations of parameters, identifies the global uncertainty of the DRC. ${ }^{96}$

\section{RESULTS AND DISCUSSION}

\section{Mechanism Generation for $\mathrm{CO}_{2}$ Hydrogenation on Ni(111)}

The initial set of 500 generated mechanisms with the coarse settings produced considerably different microkinetic mechanisms, with large variations in overall size, possible gas-phase products and adsorbates (see Figure S15). All generated mechanisms along with the evaluation are made publicly available in ref 78 . The number of species and reactions in the core ranged from 21 to 64 species and 20 to 450 reactions; the edge contained up to 360 more species and 1,053 different reactions. Mechanisms with many species/reactions were typically unreactive, which seems counterintuitive at first, but it is a consequence of the flux-based mechanism-expansion procedure. The variability in mechanism size and reactivity is not a flaw of the method, nor is it unique to automated mechanism generation; instead, it is a natural consequence of the variability in model parameters within their stated uncertainties. Different density functionals that give systematically different (but otherwise correlated) energetics will result in different mechanisms; e.g. the microkinetic models proposed by Vogt et al. ${ }^{10}$ and Lozano-Reis et al. ${ }^{12}$ also show a different number of species and reactions. The fact that most literature mechanisms contain fewer species/reactions has more to do with the computational cost of potential energy surface exploration than the intrinsic complexity of the kinetics. 
a
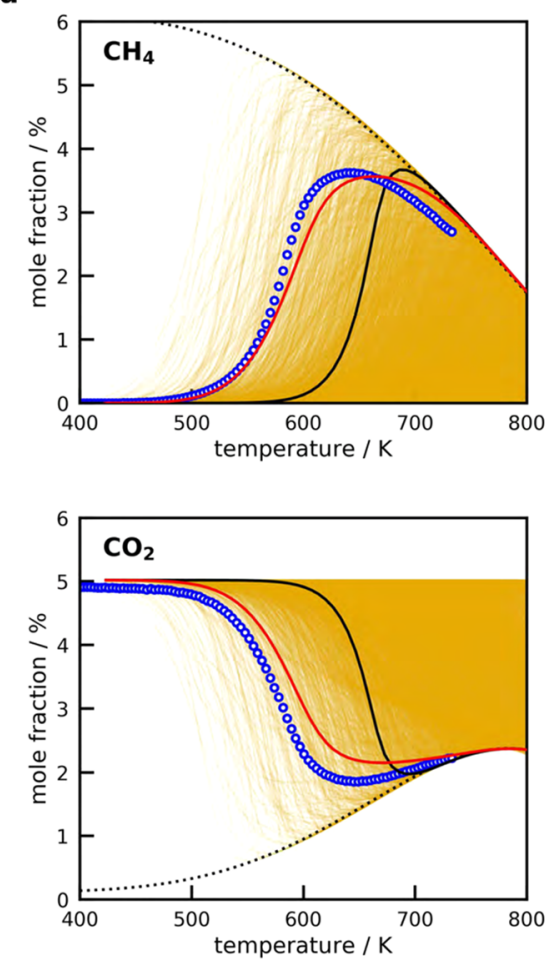

b

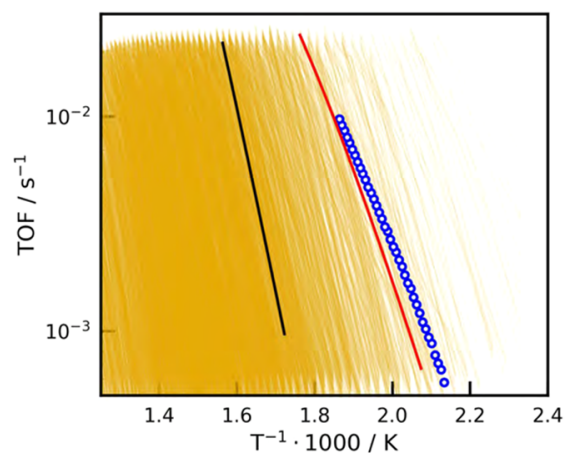

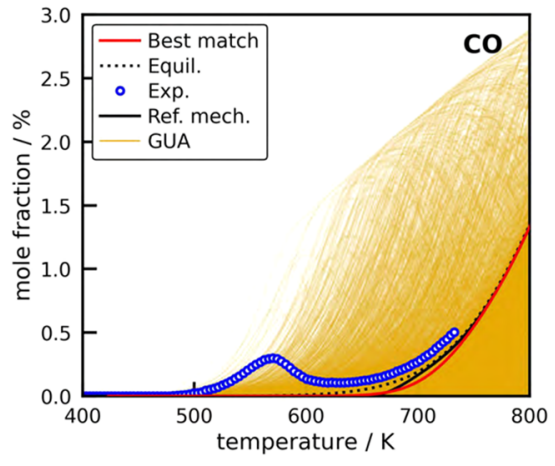

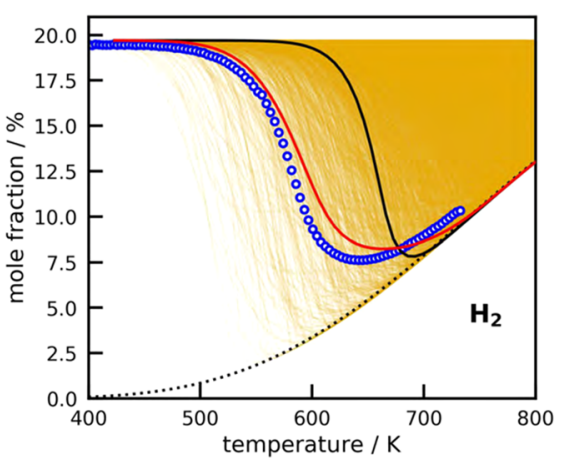

C

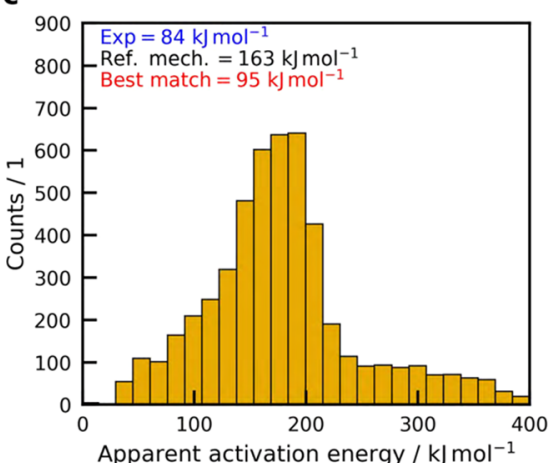

d
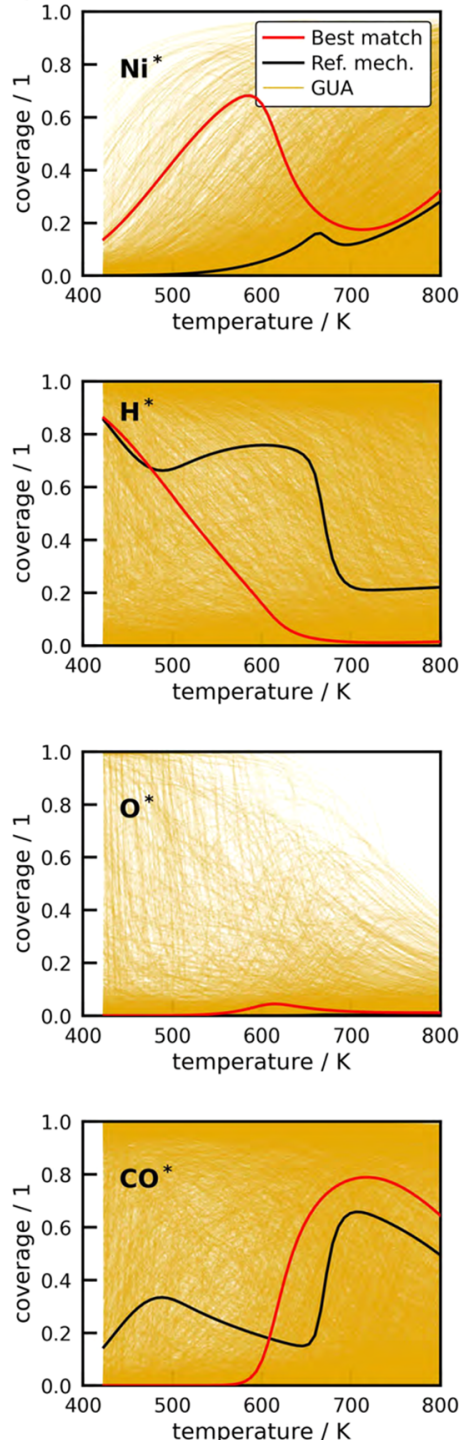

Figure 2. (a) Comparison of measured (open blue circle) and simulated (lines) mole fractions (on dry basis) for the temperature-scanning experiment using the microkinetic models generated by RMG. The dotted black line corresponds to the thermodynamic equilibrium, the solid black line to the generated reference mechanism, and the solid red line to the mechanism with closest agreement to the data. The gold-shaded area contains the model solutions of all generated mechanisms, where each mechanism is represented by a solid line. A higher intensity indicates that more simulation results fall into this area. (b) Comparison of the measured and predicted TOFs. (c) Histogram of apparent activation energies calculated from the slope of the TOFs. (d) Simulation results for the four species with highest coverage. The black line is the reference mechanism and the red line is the microkinetic model with closest agreement to the data.

Mechanism developers are forced to make assumptions to reduce complexity that are not based on actual rates but rather experience, which adds bias. ${ }^{33}$ If we performed the mechanism generation with only one set of parameters, similar to a single DFT study, we would have missed pathways and intermediates that are possible in the uncertainty range.

Figure 1a illustrates the full reaction network discovered from the coarse RMG settings, when all unique species and reactions from all 500 generated mechanism are merged together. RMG discovered 64 unique species and 450 reactions in the core mechanism, with an additional 426 species and 1,205 reactions in the edge. RMG successfully predicted the methanation of $\mathrm{CO}_{2}$ with various pathways for $\mathrm{CH}_{4}$ formation. In addition to the expected products of $\mathrm{CH}_{4}, \mathrm{CO}$, and $\mathrm{H}_{2} \mathrm{O}$, RMG predicted numerous other gas-phase species such as ethene, ethane, propane, formaldehyde, methanol, ethanol, formic acid, and acetic acid. Analysis of the edge revealed that RMG considered pathways that lead to larger alkanes, alkenes, alcohols, and acids, with a maximum chain length of $\mathrm{C}_{6}$. Although RMG successfully found multiple gas-phase products, that does not imply that these species are produced in meaningful quantities. Simulations with all 500 mechanisms demonstrate that only $\mathrm{CH}_{4}, \mathrm{CO}$, and $\mathrm{H}_{2} \mathrm{O}$ are the main products for $\mathrm{CO}_{2}$ hydrogenation on $\mathrm{Ni}(111)$ within the uncertainty range (a few percent) (see Figure S16), but the selectivity between $\mathrm{CH}_{4}$ and $\mathrm{CO}$ depends on the combination of parameters. The result is anticipated because $\mathrm{Ni}$ is a selective methanation ${ }^{7,9}$ or RWGS catalyst ${ }^{12,19,20}$ depending on the conditions. The side products with the highest yield is ethane, with concentrations of a few ppm; the other gas-phase species had concentrations of a few $\mathrm{ppb}$. Ethane and propane were also observed experimentally over $\mathrm{Ni} / \mathrm{Al}_{2} \mathrm{O}_{3}{ }^{97,98}$ and $\mathrm{Ni} /$ 
$\mathrm{SiO}_{2}$ catalysts, ${ }^{10}$ which suggests that these pathways do indeed exist.

Although it would be feasible to perform sensitivity analyses for these larger mechanisms, it is neither practical nor useful. Additional gas-phase products, and the numerous surface intermediates that are necessary for their production, do not influence the main $\mathrm{CH}_{4}$ or $\mathrm{CO}$ formation pathways. For the fine sampling (5,000 RMG runs), the maximum number of carbon atoms was restricted to 3 and the tolerance parameters were loosened to simplify the more detailed mechanism analysis and to concentrate on the kinetically more significant pathways. The reaction network that results from the fine generation process is illustrated in Figure $1 \mathrm{~b}$.

The mechanism for $\mathrm{CO}_{2}^{*}$ methanation is grouped into three main pathways: the formate path (via $\mathrm{HCOO}^{*}$ ), the carboxyl path (via $\mathrm{COOH}^{*}$ ), and the redox/carbide pathway with a direct dissociation of $\mathrm{CO}_{2}^{*}$ to $\mathrm{CO}^{*} .{ }^{10,12,70}$ In the formate path, $\mathrm{CO}_{2}^{*}$ is activated by $\mathrm{H}^{*}$ at the carbon atom. $\mathrm{HCOO}^{*}$ then dissociates to formyl $\left(\mathrm{HCO}^{*}\right)$, which is further hydrogenated to hydroxymethylene $\left(\mathrm{HCOH}^{*}\right)$ and hydroxymethyl $\left(\mathrm{H}_{2} \mathrm{COH}^{*}\right)$. The $\mathrm{C}-\mathrm{O}$ bond in hydroxymethyl is then cleaved, forming hydroxyl $\left(\mathrm{OH}^{*}\right)$ and methylene $\left(\mathrm{CH}_{2}^{*}\right)$. In the carbonyl pathway, $\mathrm{CO}_{2}^{*}$ activation occurs at the oxygen atom; the resulting $\mathrm{COOH}^{*}$ can then cleave either the $\mathrm{C}-\mathrm{O}$ or $\mathrm{C}=\mathrm{O}$ bond to yield carbon monoxide $\left(\mathrm{CO}^{*}\right)$ or hydroxymethylidyne $\left(\mathrm{COH}^{*}\right)$, respectively. Direct $\mathrm{CO}_{2}^{*}$ dissociation occurs in the redox pathway forming $\mathrm{CO}^{*}$, which can desorb directly or undergo further bond fission to form surface carbon that is subsequently hydrogenated to $\mathrm{CH}_{4}$. These three pathways are not separate mechanisms; rather, they are coupled pathways entangled by various abstraction and dissociation reactions. ${ }^{10,12}$ Importantly, as depicted in Figure $1 \mathrm{~b}, \mathrm{RMG}$ found all three major $\mathrm{CO}_{2}^{*}$ activation routes, as well as the numerous cross-coupling reactions. The constrained mechanisms still contains the production of ethane via various $\mathrm{C}-\mathrm{C}$ coupling reactions like $\mathrm{C}-\mathrm{CH}_{x}$ $\mathrm{CH}_{x}-\mathrm{CH}_{y}$, or $\mathrm{CH}_{y}-\mathrm{CO}$.

The combined reaction network discovered by RMG for all 5,000 samples within the correlated uncertainty range shows that only 35 species and a total of 150 reactions are kinetically relevant for the system. Of these reactions, 9 are adsorption/ desorption, 36 are dissociation, and 105 are abstraction (see Table S9). The high number of abstraction reactions is in sharp contrast to most of the literature studies, where only dissociation reactions are considered. ${ }^{10,14,15}$ Some abstraction reactions were considered by Lozano-Reis et al., ${ }^{12}$ but usually, these types of reactions are overlooked due to the combinatorial growth of possible reactions to consider. ${ }^{33,34}$ The discovered abstraction reactions are not limited to the oxidative dehydrogenation reactions of $\mathrm{R}-\mathrm{H}$ by $\mathrm{O}^{*}$ or $\mathrm{OH}^{*}$, which are the ones that are most often considered in microkinetic models. ${ }^{12,72}$ Larger moieties can be abstracted further down the chain, which creates a whole new set of reactions that are currently not considered in the literature. The presence of these abstraction reactions nicely illustrates the full potential of automated mechanism generation.

The $\mathrm{C}_{1}$ species discovered are consistent with prior literature mechanisms, ${ }^{10,12,14,15,70}$ with the most sophisticated study by Lozano-Reis et al. ${ }^{12}$ It is worth emphasizing that none of these species were included in the input, and thus RMG did not "know" to look for them. Additionally, several new abstraction reactions were predicted by RMG, which have not previously been considered for methanation. Furthermore, none of the other studies includes the formation of $\mathrm{C}_{2}$ species, even though it is experimentally observed. ${ }^{10,97,98}$ A predictive microkinetic mechanism should capture all the important pathways that lead to experimentally observable products, even if $\mathrm{C}-\mathrm{C}$ coupling does not represent a major competing pathway for methanation on $\mathrm{Ni}(111)$ under the present conditions.

\section{Microkinetic Modeling}

Figure 2 shows the experimentally recorded concentration profiles for all species measured during the temperaturescanning experiment on a dry basis (except Ar). The carbon mass balance is always closed within $\pm 2 \%$. With the current setup, it is not possible to accurately measure the $\mathrm{H}_{2} \mathrm{O}$ concentration due to partial condensation in the transfer lines. The experiments show a starting temperature for the $\mathrm{CH}_{4}$ formation around $500 \mathrm{~K}$, followed by a pronounced $\mathrm{CO}$ peak with a maximum at $550 \mathrm{~K}$. A maximum $\mathrm{CH}_{4}$ formation rate is observed at a temperature of $650 \mathrm{~K}$, with a $\mathrm{CH}_{4}$ selectivity of 97\%. The $\mathrm{CH}_{4}$ concentration decreases at higher temperatures, whereas the $\mathrm{CO}$ concentration increases according to thermodynamic equilibrium that is reached in the experiment at temperatures beyond $700 \mathrm{~K}$. An activation energy of $84 \mathrm{~kJ}$ $\mathrm{mol}^{-1}$ was determined, which is comparable to other $\mathrm{Ni} / \mathrm{SiO}_{2}$ catalysts. ${ }^{10,74,99,100}$ Results from the microkinetic model generated by RMG with the reference settings show a significantly lower activity at lower temperatures. $\mathrm{CH}_{4}$ formation starts at $600 \mathrm{~K}$ and reaches the maximum rate at $700 \mathrm{~K}$. The production of CO starts at a temperature of $650 \mathrm{~K}$ and directly reaches the equilibrium concentration.

Also included in Figure 2 are the reactor simulations using the 5,000 different mechanisms. All generated mechanisms adhere to the thermodynamic constraints, which was confirmed according to literature guidelines ${ }^{101,102}$ (see SI). The predicted profiles range from almost no $\mathrm{CH}_{4}$ formation even at high temperatures to an increased activity at low temperatures, with maximums of $5 \%$ at $600 \mathrm{~K}$. Figure $2 \mathrm{~b}$ presents the turnover frequency (TOF) for the system, which was calculated from the average $\mathrm{CH}_{4}$ formation rate and the amount of exposed $\mathrm{Ni}$ surface atoms in the PFR assuming differential conditions. Figure $2 c$ presents a histogram of the corresponding apparent activation energy determined from the slope of the TOF. Most of the mechanisms exhibited very low activity, as seen by the dense cluster of lines at higher temperatures in the TOF plot and the broad range of comparatively high activation energies. However, there are also combinations of parameters which result in a very high methanation activity. This distribution in activity is consistent with the Sabatier principle; high activity is only obtained when key intermediates are bound to the catalyst neither too strongly nor too weakly. The broad range in reactivity is a consequence of the $\pm 0.3 \mathrm{eV}$ uncertainty in energies (even under consideration of correlation) obtained from electronic structure calculations, which has been pointed out by other studies as well. ${ }^{52,58}$ In other words, for some combination of parameters, the $\mathrm{Ni}(111)$ facet is inactive for methanation but only produces $\mathrm{CO}$ via the RWGS reaction, and is consequently not the active site for methanation. ${ }^{12}$ In contrast, the $\mathrm{Ni}(111)$ surface exhibits quite a high methanation activity for other parameter combinations, also in agreement with the literature, ${ }^{10,15}$ and could, therefore, be the active site. The correct quantification of correlated uncertainties in the DFTderived parameters in this study explains the opposite observations and conclusions from Lozano-Reis et al. ${ }^{12}$ and 
a
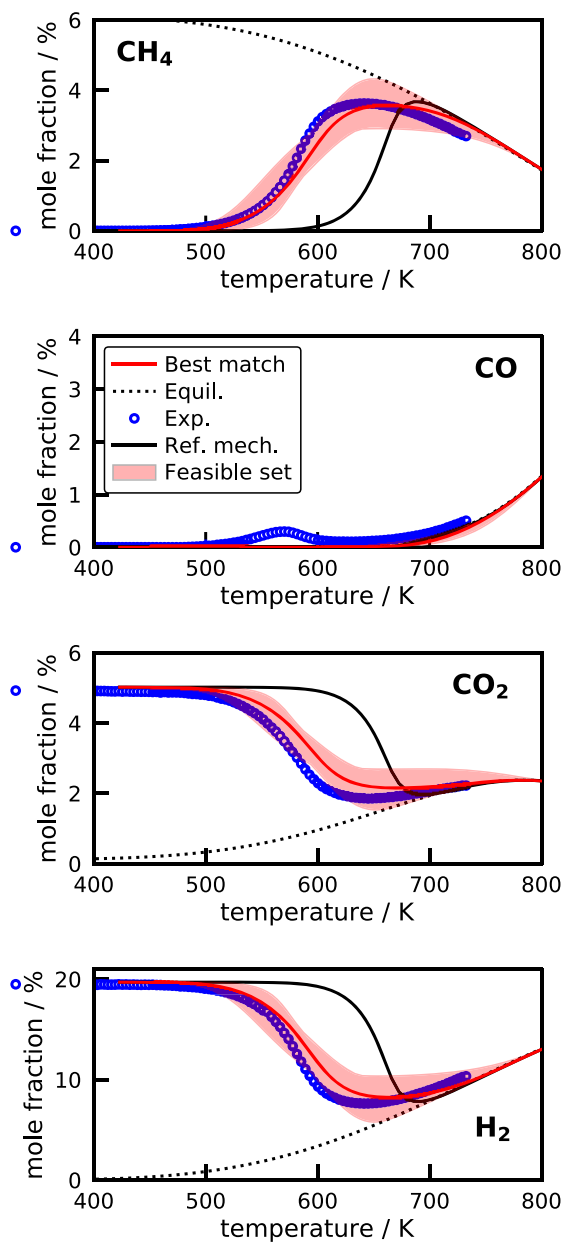

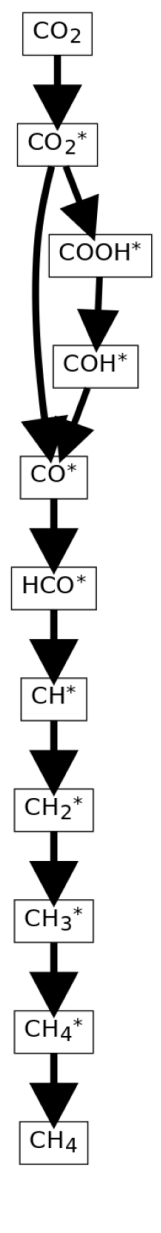

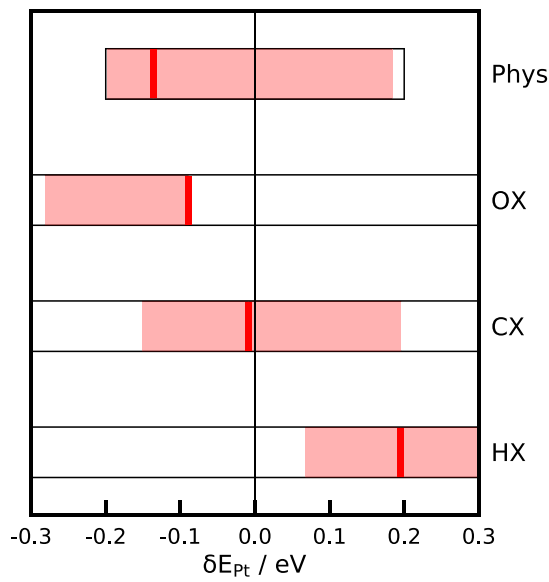

d

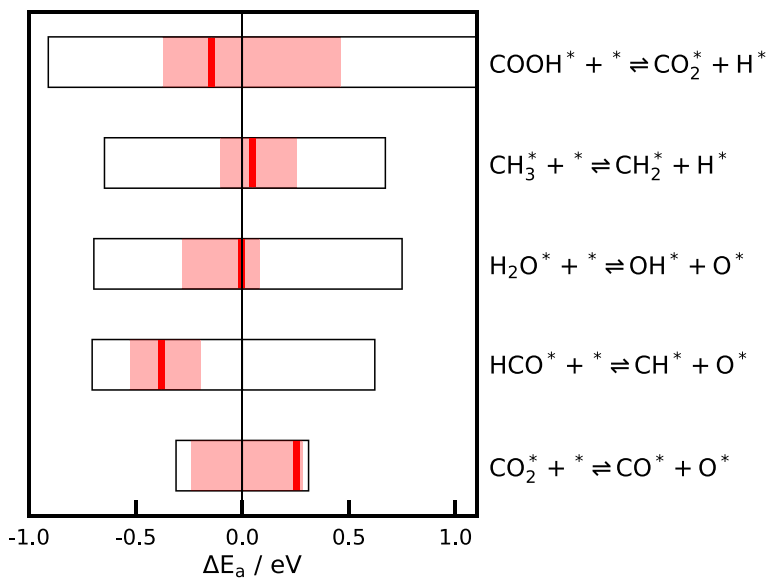

Figure 3. (a) Comparison of the experiments with the mechanisms with the closest agreement to the data from the global uncertainty analysis. The solid black line is the base-case mechanism; the solid red line is the mechanism with the lowest MAPE, and the shaded pink region contains the mechanisms that are within $+30 \%$ of the lowest MAPE (the "feasible set"). (b) $\mathrm{CH}_{4}$ formation pathways of the mechanism with the lowest MAPE compared to the experimental data. Only the intermediates and pathways that contribute significantly to the $\mathrm{CH}_{4}$ formation rate are displayed. (c) Perturbation parameters $\delta E_{\mathrm{Pt}}^{\mathrm{AX}}$ for the LS descriptors that specify the uncertainty in the thermochemistry and (d) the perturbation in the activation energies for the most important reactions based on the sensitivity analysis. The black box shows the possible range of values (uncertainty), and the pink area encloses the values from the feasible sets. The red line reports the parameter of the best match.

Vogt et al. ${ }^{10}$ on the activity of $\mathrm{Ni}(111)$. Accordingly, it is difficult to establish the importance of the $\mathrm{Ni}(111)$ facet for $\mathrm{CO}_{2}$ methanation with confidence, given the current parametric uncertainty of DFT data, which implies that a DFT study cannot be more conclusive either.

Figure $2 \mathrm{~d}$ summarizes the surface site fractions for the vacant site $\left(\mathrm{Ni}^{*}\right)$ and the three adsorbates with the highest coverages $\left(\mathrm{H}^{*}, \mathrm{O}^{*}, \mathrm{CO}^{*}\right)$. Profiles for other adsorbates, as well as for $\mathrm{CO}_{2}$ conversion, $\mathrm{CH}_{4}$ selectivity, and $\mathrm{CH}_{4}$ yield are provided in the SI. Depending upon the particular combination of parameters, the surface can be entirely vacant, completely blocked by either $\mathrm{H}^{*}$ or $\mathrm{CO}^{*}$, or in a few instances, covered by $\mathrm{O}^{*}$. This range in coverage suggests that it is challenging to make a priori assumptions regarding the most-abundant surface intermediates (MASI) with any confidence for this system, given the current accuracy of DFT-derived models, but it can be limited to these three species. The predicted coverages of the reference model are in contrast to the results reported by Vogt et al., ${ }^{10}$ who report a $\mathrm{Ni}(111)$ surface that was completely saturated with $\mathrm{CO}^{*}$, but they did not include the possibility of $\mathrm{CO}^{*}$ desorption. In contrast, Lozano-Reis et al. ${ }^{12}$ obtained a nearly vacant $\mathrm{Ni}(111)$ surface with just around $10 \% \mathrm{H}^{*}$ coverage. Heine et al. ${ }^{13}$ observed $\mathrm{CO}^{*}$ on the $\mathrm{Ni}(111)$ surface at elevated temperatures during $\mathrm{CO}_{2}$ methanation, which agrees with the model predictions.

From the computed profiles in Figure 2a, it is possible to identify the subset of mechanisms in closest agreement with the experimental data by computing the mean-absolute percentage error (MAPE) for the measured and predicted gas-phase concentrations of $\mathrm{CH}_{4}, \mathrm{CO}_{2}, \mathrm{H}_{2}$, and $\mathrm{CO}$. The mechanism that had the lowest MAPE for the predictions of all four species against the experimental data is shown as a red line in Figure 2. Additionally, there are multiple combinations of parameters that are within $30 \%$ of the lowest MAPE. This ensemble of feasible mechanisms, along with the closest match, is illustrated by the shaded pink region in Figure 3a. It should be emphasized that the red line in Figure 2 and 3, although in quantitative agreement with the measured data, is not the result of an optimization algorithm. All the parameters of the microkinetic model were varied randomly in the global uncertainty assessment within their stated uncertainty ranges 
consistently with their correlated uncertainties. Admittedly, the approach of drawing a few thousand quasi-random samples from a parameter space and determining the MAPE to the experimental data can be considered as a very crude fitting procedure. The agreement with measured concentrations certainly could be improved by optimizing the pre-exponential factors, optimizing the binding energies and activation energies (within a narrower range), and accounting for coverage dependence, ${ }^{31,32}$ but such an attempt at optimization is beyond the scope of the present work. Within the correlated uncertainty space of the microkinetic model parameters for the $\mathrm{Ni}(111)$ facet, there are feasible sets that can describe the $\mathrm{CO}_{2}$ methanation experiments on the $\mathrm{Ni} / \mathrm{SiO}_{2}$ catalyst. Consistent with the guidelines for mechanism analysis outlined by Bhandari et al., ${ }^{32}$ with the additional constraints of correlated uncertainties, $\mathrm{Ni}(111)$ can be considered as an active site for the $\mathrm{CO}_{2}$ methanation, and we shift our attention to the possible methane formation pathways to gain insights into the methanation mechanism.

The essential pathways for the methanation of $\mathrm{CO}_{2}$ on $\mathrm{Ni}(111)$ for the mechanism in closest agreement to the data are illustrated in Figure $3 \mathrm{~b}$. At a temperature of $573 \mathrm{~K}, 75 \%$ of $\mathrm{CO}^{*}$ is produced via the direct dissociation of $\mathrm{CO}_{2}^{*}$, and the remaining $25 \%$ comes from various reactions in the carboxyl path, which contradicts conclusion from Vogt et al., ${ }^{10}$ who argued that this path does not contribute to $\mathrm{CH}_{4}$ formation. The only significant source of $\mathrm{CH}^{*}$ (and thus ultimately $\mathrm{CH}_{4}^{*}$ ) is from the dissociation of $\mathrm{HCO}^{*}, \mathrm{HCO}^{*} \rightarrow \mathrm{CH}^{*}+\mathrm{O}^{*}$. According to the DRC analyses for all 5,000 mechanisms, there is no combination of parameters in which the formate path, $\mathrm{CO}_{2}{ }^{*} \rightarrow \mathrm{HCOO}^{*} \rightarrow \mathrm{HCO}^{*}$, is a significant source of $\mathrm{HCO}^{*}$ (see SI for details). Instead, the overwhelming majority of $\mathrm{HCO}^{*}$ is produced via hydrogenation of $\mathrm{CO}^{*}, \mathrm{CO}^{*}+\mathrm{H}^{*} \rightarrow$ $\mathrm{HCO}^{*}$, where $\mathrm{CO}^{*}$ is produced via the redox and carboxyl path. This result is in agreement with Heine et al., ${ }^{13}$ who did not observe $\mathrm{HCOO}^{*}$ during $\mathrm{CO}_{2}$ methanation on $\mathrm{Ni}(111)$ in operando XPS studies. Although $\mathrm{HCOO}^{*}$ has been observed in some spectroscopic studies $9,10,103,104$ during $\mathrm{CO}_{2}$ hydrogenation on $\mathrm{Ni}$, our findings support the conclusion that $\mathrm{HCOO}^{*}$ is a spectator species. ${ }^{19,103,104}$

Figure $3 c$ presents the best match and feasible set for the four parameters that govern the uncertainty of the correlated binding energies. The results suggest that all mechanisms in the feasible set require an increase to the heat of formation for $\mathrm{H}^{*}$ (i.e., destabilize), and a decrease to the heat of formation of species that bind through oxygen. Variability in the binding energy of adsorbates that bind through carbon, in contrast, is not as important. Figure 3d presents similar results for the top five reactions (see Sensitivity Analysis); the most significant deviation from the base case is for $\mathrm{HCO}^{*}$ dissociation, where the feasible set is more tightly clustered around a reduction in the activation energy of $0.4 \mathrm{eV}$.

A subset of the potential energy diagram that highlights the main pathway is presented in Figure 4. The individual yellow lines represent different possible mechanisms. The large spread in possible values in the initial portion of the potential energy diagram is due primarily to the fact that there are $8 \mathrm{H}^{*}$. Adsorbates that bind through carbon (i.e., $\mathrm{C}^{*}, \mathrm{CO}^{*}, \mathrm{HCO}^{*}$ ) represent the various minima for the first half of the diagram. These minima are all shifted by the same perturbation according to the usage of the LS relation for the propagation of the uncertainty. ${ }^{105}$ The difference between the base case (solid black line) and the best match (solid red line),

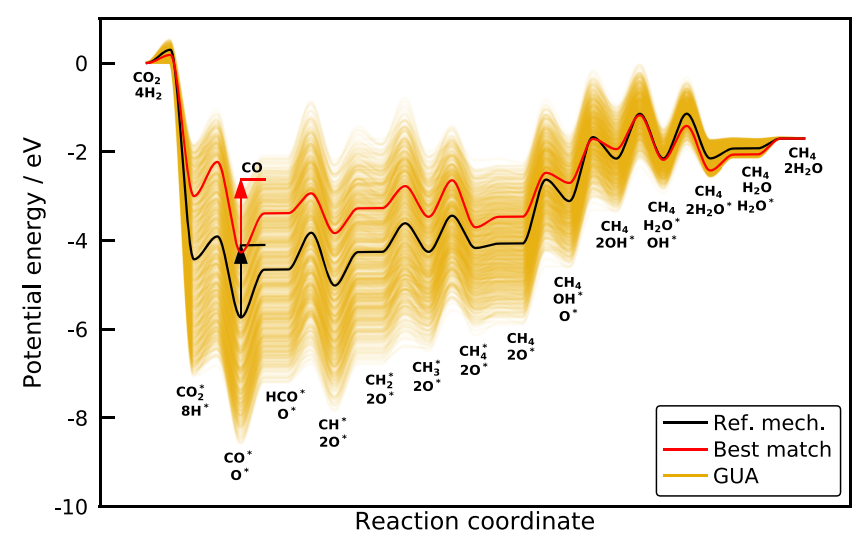

Figure 4. Potential energy diagram for the most dominant $\mathrm{CH}_{4}$ formation pathway. The balancing $\mathrm{H}^{*}$ atoms are omitted for clarity after the adsorption step. Only a reduced number of 1,000 mechanisms is displayed for clarity.

combined with the results from Figure $3 \mathrm{~d}$, indicates that the majority of the change from the black line to the red line comes from the weakening of the $\mathrm{H}^{*}$ binding energy by 0.2 $\mathrm{eV}$; the binding energies for adsorbates that bind through carbon are not changed significantly. Adsorbates that bind through oxygen (i.e., $\mathrm{O}^{*}, \mathrm{OH}^{*}$ ) represent the second half of the diagram. Here we see that a decrease in the heats of formation (stabilizing) of $0.1 \mathrm{eV}$ of species that bind through oxygen is needed to improve the agreement. The parametrized mechanism of this reduced network is provided in Table S10 and the complete mechanism in Table S11.

As suggested by Figure 4, $\mathrm{H}^{*}$ and $\mathrm{CO}^{*}$ are most likely to be the MASIs on the $\mathrm{Ni}(111)$ surface, which also agrees with the simulation results. High activation barriers are obtained for $\mathrm{HCO}^{*}$ formation and dissociation, as well as the hydrogenation of $\mathrm{O}^{*}$ and $\mathrm{OH}^{*}$. $\mathrm{CO}^{*}$ does not desorb in the feasible set because the desorption barrier is significantly higher than the hydrogenation to $\mathrm{HCO}^{*}$. There are several routes for the activation of $\mathrm{CO}_{2}^{*}$ in the carboxyl pathway that have comparable barriers (see Table S10 and Figure S21 for the free energy surface); either via reaction with $\mathrm{H}^{*}$, or $\mathrm{CO}_{2}^{*}$ can abstract a $\mathrm{H}$ atom from $\mathrm{OH}^{*}$ or $\mathrm{H}_{2} \mathrm{O}^{*}$. After the creation of $\mathrm{COOH}^{*}$, there are two possible routes with comparable free energy barriers for its decomposition, with the cleavage of $\mathrm{C}=$ $\mathrm{O}$ or $\mathrm{C}-\mathrm{OH}$. The formation of $\mathrm{CO}$ from $\mathrm{COH}$ requires an additional step, and the oxidative dehydrogenation of $\mathrm{COH}^{*}$ provides a significantly lower barrier than the direct dissociation, in agreement with results from the activation of $\mathrm{CO}$ on $\mathrm{Co}$ in the Fischer-Tropsch synthesis. ${ }^{27}$ BEP relations providing barriers for bimolecular reactions are coupled to the thermochemistry of multiple species, so the uncertainty range of the barrier can be large. Consequently, the activity of these pathways, which are all relatively close in free energy, can contribute to various extents to the $\mathrm{CH}_{4}$ formation in the parametric uncertainty range. Figure 4 and Figure S21 show that it is currently difficult to predict a certain path within the given accuracy of the present DFT functionals. ${ }^{51,59,60}$

Although the microkinetic model can accurately predict the measured $\mathrm{CO}_{2}$ conversion and $\mathrm{CH}_{4}$ yield, it is currently not able to accurately predict the correct selectivities toward $\mathrm{CH}_{4}$ and $\mathrm{CO}$ at low temperatures (see Figure $2 \mathrm{a}$ and Figure S18). Some simulations show a $\mathrm{CO}$ peak at low temperatures, but this can only occur if the binding energy of $\mathrm{CO}$ is lowered, so that $\mathrm{CO}^{*}$ can partially desorb from the catalyst surface before 
a

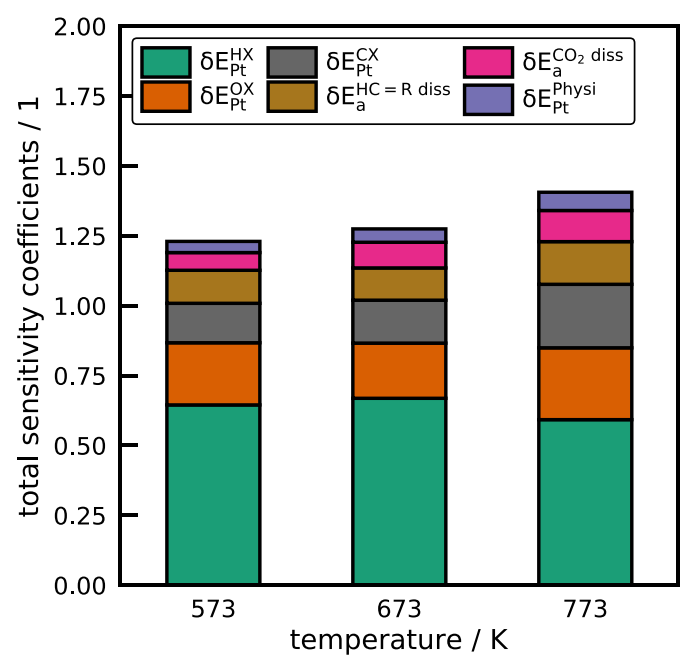

b

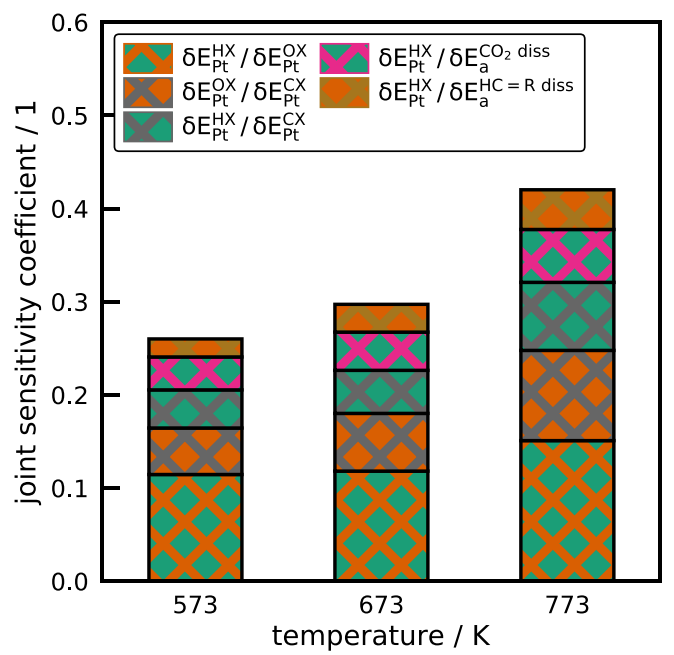

Figure 5. (a) Total sensitivity coefficients for the six most influential input parameters on the uncertainty of the $\mathrm{CH}_{4}$ concentration at different temperatures. (b) Joint sensitivity coefficients with the highest values. The hash combines the pair of colors from the total sensitivity coefficients.

a

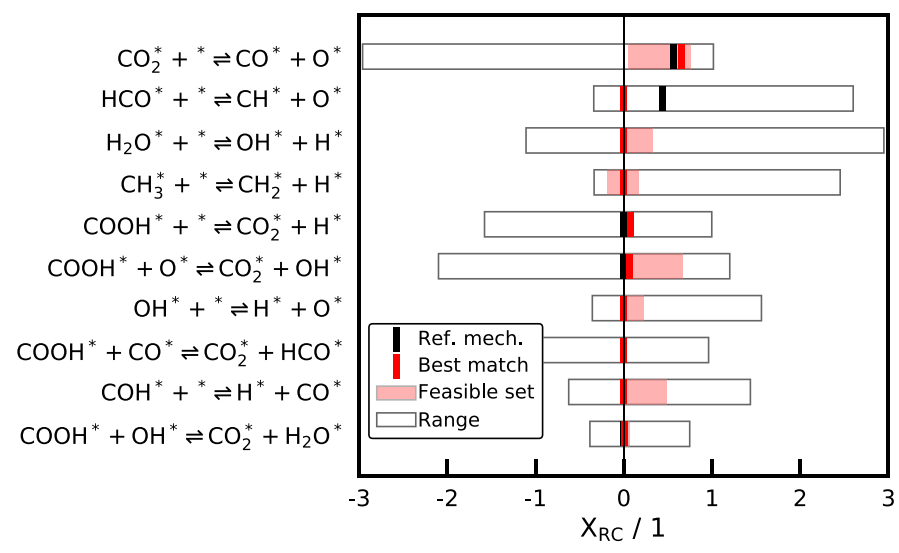

C

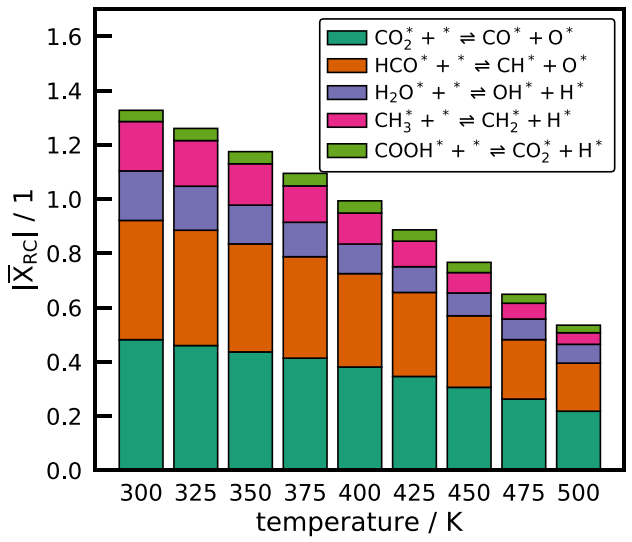

b

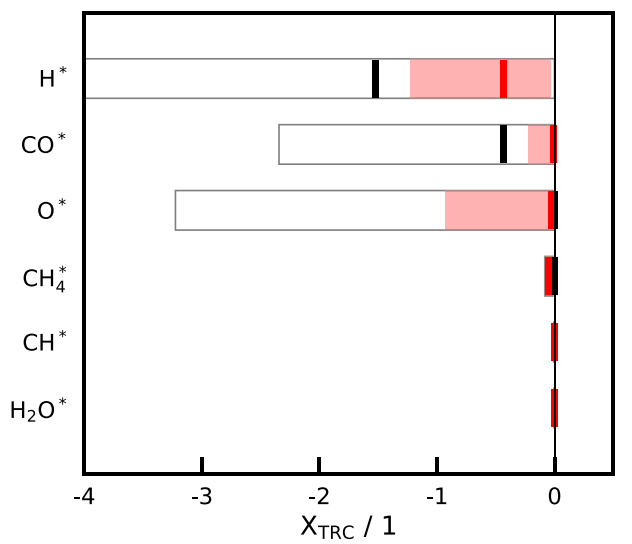

d

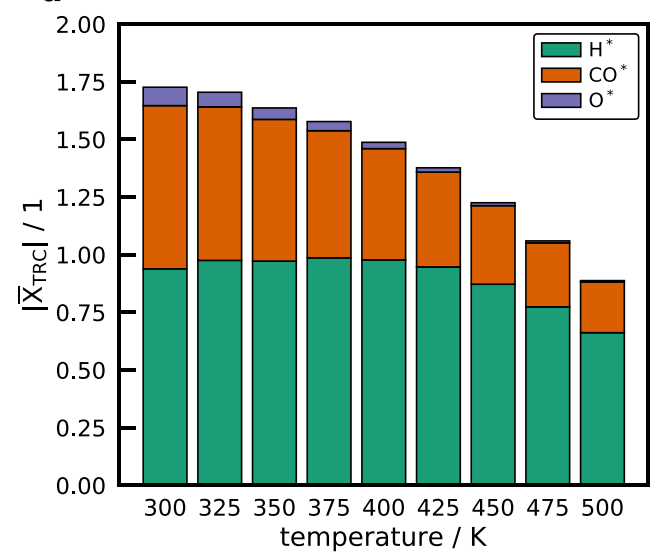

Figure 6. DRC for (a) reactions and (b) adsorbates at $573 \mathrm{~K}$. Only the most important reactions/species are presented, with the reactions/species with the highest absolute average DRC at the top. The black box represents the range of the DRC values for all possible mechanisms; the black line is the reference mechanism; the red line and pink shaded region are the best mechanism and feasible set, respectively. Averaged absolute (c) DRC and (d) thermodynamic DRC at different temperatures.

the activation barrier of the step consuming the $\mathrm{CO}^{*}$ is overcome. A likely explanation for the discrepancy in the selectivity is coverage dependence. ${ }^{106}$ As mentioned above, no coverage effects were considered in the present study. However, adsorbates like $\mathrm{CO}^{*}$ or $\mathrm{O}^{*}$ show repulsive interactions, which destabilize their binding energies. ${ }^{20,107}$ In general, including coverage effects will affect the binding strength of species and transition states and can significantly alter the potential energy surface. ${ }^{32,53,82}$ Thus, we suspect that the inability of our model to describe the $\mathrm{CO}$ desorption peak 

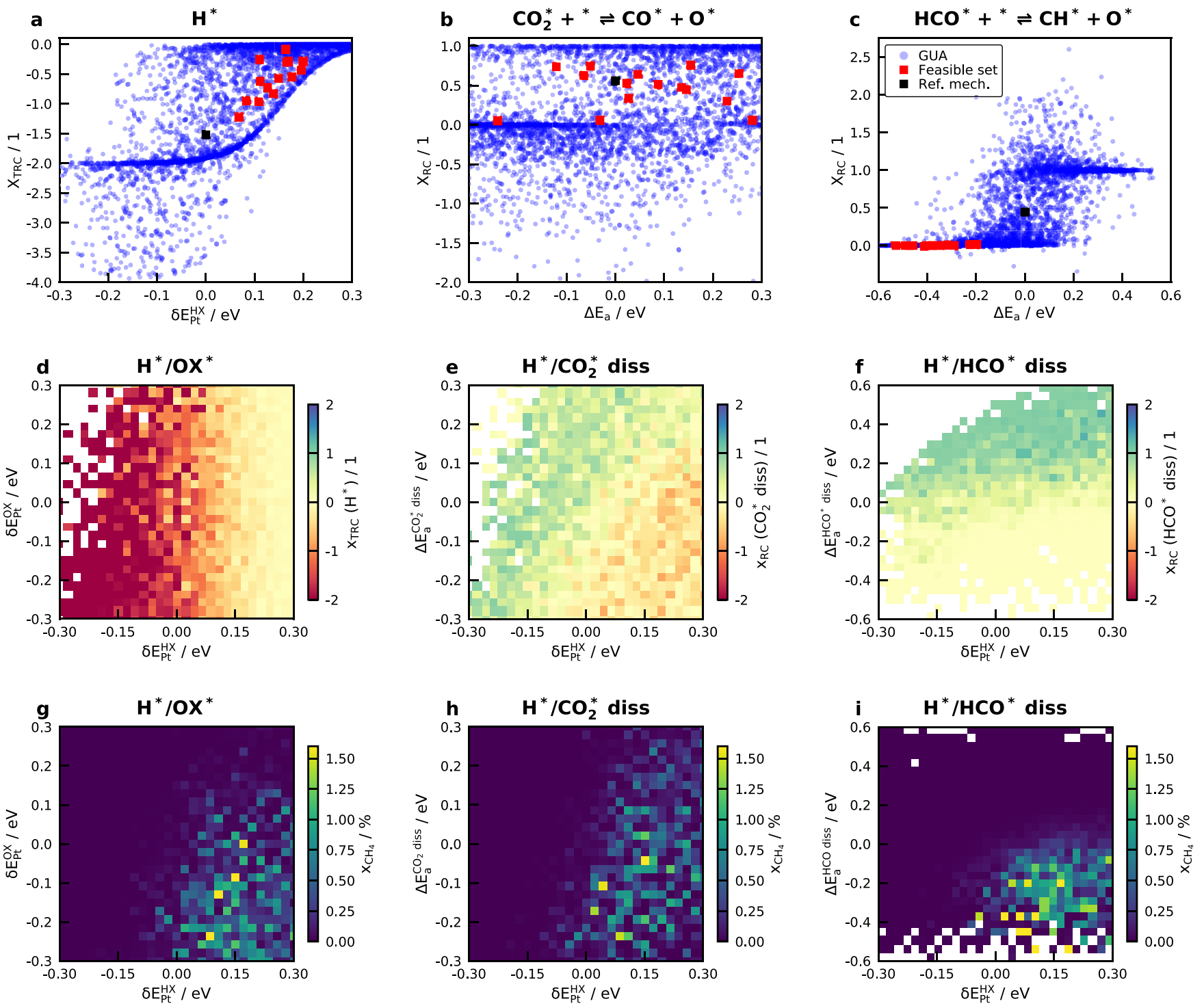

Figure 7. Scatter plots for (a) $X_{\mathrm{TRC}}$ of $\mathrm{H}^{*}$ versus change in binding energy, (b) $X_{\mathrm{RC}}$ of $\mathrm{CO}_{2}^{*}$ dissociation, and (c) $X_{\mathrm{RC}}$ of $\mathrm{HCO}^{*}$ dissociation versus change in activation energy. Red squares are the values for mechanisms in the feasible set, and the black square is the reference mechanism. (d) Heatmap for $X_{\mathrm{TRC}}$ of $\mathrm{H}^{*}$ over $\delta E_{\mathrm{Pt}}^{\mathrm{HX}}$ and $\delta E_{\mathrm{Pt}}^{\mathrm{OX}}$. Heatmaps for the DRC for the (e) $\mathrm{CO}_{2}^{*}$ and (f) $\mathrm{HCO}^{*}$ dissociation as a function of their change in activation energy and $\delta E_{\mathrm{Pt}}^{\mathrm{HX}}$. Heatmaps for $\mathrm{CH}_{4}$ mole fraction as a function of $\delta E_{\mathrm{Pt}}^{\mathrm{HX}}$ and $(\mathrm{g}) \delta E_{\mathrm{Pt}}^{\mathrm{OX}},(\mathrm{h})$ activation energy of $\mathrm{CO}_{2}^{*}$ dissociation, and $(\mathrm{i})$ activation energy of $\mathrm{HCO}^{*}$ dissociation. The data are sorted into a $30 \times 30$ grid, and all sensitivity coefficients or $\mathrm{CH}_{4}$ mole fractions are averaged in these bins. All results are for a temperature of $573 \mathrm{~K}$.

is a consequence of neglecting coverage effects, not due to missing kinetic pathways. The inclusion of coverage effects directly in the mechanism generation procedure is the aim of future studies.

\section{Analysis}

In a microkinetic model, not all species and reactions are equally important; typically, the variability of the output is determined by just a few species and reactions. The total sensitivity coefficients for the $\mathrm{CH}_{4}$ concentration, determined from the polynomial chaos expansion, are displayed in Figure 5 a. Of the 65 parameters that were varied in the global uncertainty analysis, the parameter with the largest sensitivity index is for $\delta E_{\mathrm{Pt}}^{\mathrm{HX}}$, which corresponds to the heat of formation of $\mathrm{H}^{*}$. This result is unsurprising, given that hydrogenation reactions are critical in methanation and that the heat of formation of $\mathrm{H}^{*}$ affects activation barriers via BEP relation and reverse rates via the equilibrium constant. The next most important parameters are $\delta E_{\mathrm{Pt}}^{\mathrm{OX}}$ and $\delta E_{\mathrm{Pt}}^{\mathrm{CX}}$ for the heats of formation of adsorbates that bind through oxygen and carbon, respectively. The larger influence of thermochemistry than kinetics was observed in other studies as well. ${ }^{52}$

The fourth most important parameter is the reference activation energy for the reaction family for the dissociation of $\mathrm{HC}=\mathrm{R}$ double bonds. This family provides kinetics for the dissociation of the $\mathrm{C}=\mathrm{O}$ bond in $\mathrm{HCO}^{*}$, which many studies consider to be the RDS. ${ }^{10,15}$ Moreover, this reaction is the most important pathway for $\mathrm{CH}^{*}$ formation observed in the mechanisms with best agreement to the experiments (see Figure $3 \mathrm{~b}$ and Figure 4 ). The next most sensitive reaction is $\mathrm{CO}_{2}^{*}$ dissociation, which is also thought to be rate controlling. $^{12}$

In a complex microkinetic model, there will be higher-order interactions among the parameters, which are further amplified by the coupling of the thermochemistry with the activation 
barriers in the BEP relations. These higher-order interactions are captured by the joint sensitivity indices from the PCE method and displayed in Figure 5b. The highest joint sensitivities are caused by $\mathrm{H}^{*}$ in combination with $\mathrm{O}^{*}, \mathrm{C}^{*}$, $\mathrm{CO}_{2}^{*}$ dissociation, and the $\mathrm{HC}=\mathrm{R}$ dissociation family.

Figure 6 summarizes the results of the degree of rate control analysis. The black boxes in Figure 6a-b represent the range of possible DRC values at $573 \mathrm{~K}$ for reactions and species, respectively, that were obtained for all 5,000 mechanisms. Also included inside each box is the DRC value for the reference mechanism (vertical black line), the best match (vertical red line) and the ensemble of feasible mechanisms (shaded pink region). According to the DRC analysis, the most important reactions are the dissociation of $\mathrm{CO}_{2}^{*}$ and the dissociation of the $\mathrm{C}=\mathrm{O}$ bond in $\mathrm{HCO}^{*}$, in agreement with the results from the GSA. The results in Figure 6a-b nicely highlight the implicit assumptions in the DRC approach and associated challenges that it entails for the current accuracy of DFT-based microkinetic models. For the overwhelming majority of parameter combinations, the dissociation of $\mathrm{HCO}^{*}$ has a positive DRC, implying that increasing the rate constant will increase the rate of $\mathrm{CH}_{4}$ production. For the feasible set, however, it is zero. The dissociation of $\mathrm{CO}_{2}^{*}$, in contrast, has a $X_{\mathrm{RC}}$ that ranges from -3 to +1 . Additionally, abstraction reactions that convert $\mathrm{CO}_{2}^{*}$ to $\mathrm{COOH}^{*}$, which are frequently neglected, are rate controlling for some parameter combinations. Equally important, the actual values of $X_{\mathrm{RC}}$ for a given reaction can vary considerably. Vogt et al. ${ }^{10}$ and Zhou et al. ${ }^{15}$ report that the dissociation of $\mathrm{HCO}^{*}$ is the $\mathrm{RDS}$ on $\mathrm{Ni}(111)$, whereas Lozano-Reis et al. ${ }^{12}$ state that the dissociation of $\mathrm{CO}_{2}^{*}$ is the RDS. The present results suggest that the choice of RDS is, in fact, highly dependent on the microkinetic parameters (and thus the DFT method through which they were obtained). Indeed, both of these reactions and many others can be rate-controlling, depending upon small perturbations of parameters within a narrow uncertainty range. For the best match mechanism, $\mathrm{CO}_{2}^{*}$ dissociation has the largest $X_{\mathrm{RC}}$.

From the thermodynamic DRC, we obtain that the most important species are $\mathrm{CO}^{*}, \mathrm{H}^{*}, \mathrm{O}^{*}$, while all other adsorbates are never rate controlling over the entire uncertainty range (see Figure S25). This can be explained by the correlation between the thermodynamic DRC and the coverage of the adsorbates. ${ }^{62,108,109} \mathrm{CO}^{*}, \mathrm{H}^{*}$, and $\mathrm{O}^{*}$ are the only adsorbates which exhibit a high coverage in the given uncertainty range (see Figure $2 \mathrm{~d}$ ). More specific, $\mathrm{O}^{*}$ shows only a high coverage for few combination of parameters and the surface is predominantly covered by either $\mathrm{H}^{*}, \mathrm{CO}^{*}$, or a combination of both.

In the absence of experimental data, it would not be possible to determine a priori which mechanism will provide the closest description of reality-let alone speculate as to the reaction/ species with the highest DRC. Accordingly, averaging over the DRC of all mechanisms is a compelling way to predict how the mechanism is likely to respond in the absence of other information. Additionally, it prioritizes which rate constants or thermochemistry should be refined. Figure $6 \mathrm{c}, \mathrm{d}$ plot the average of the absolute value of the DRC at different temperatures for reactions and species, respectively. These figures demonstrate that 4 reactions and 3 species have a high DRC over the entire temperature range. Of these results, the $\mathrm{CO}_{2}^{*}$ and $\mathrm{HCO}^{*}$ dissociation, together with heats of formation for $\mathrm{H}^{*}$ and $\mathrm{CO}^{*}$, are most important, which is consistent with the GSA and the literature. ${ }^{10,12,15}$
The DRC analysis shows that from the complex reaction network with 150 elementary reactions and 35 species, only a handful have high DRC over the entire uncertainty range and the rest are never rate-controlling (see Figure S24-S25). Thus, every effort should be made to refine the kinetic and thermodynamic parameters for these reactions and species as accurately as possible. Refinement of the parameters can be conducted with more accurate DFT approaches ${ }^{110}$ or based on experiments from single crystals. ${ }^{32}$ As an example, heats of formation of $\mathrm{H}^{*}$ and $\mathrm{CO}^{*}$ on $\mathrm{Ni}(111)$ are available from single crystal studies ${ }^{111}$ and can be incorporated in a follow-up study. However, comparing Figure $6 c, d$ with Figure $6 a, b$ highlights how varied the DRC results can be, depending upon the structure of the underlying mechanism. Our results do not question the DRC concept, because it has a precise meaning for each of the generated mechanism. Rather, these results demonstrate that within the relatively narrow uncertainty range, correlated perturbations significantly alter the potential energy surface, thereby resulting in different rate-controlling reactions or intermediates. Determination of the DRC from a single DFT-derived model is, therefore, not conclusive.

A key finding in Figure $6 \mathrm{a}-\mathrm{b}$ is that critical reactions $\left(\mathrm{CO}_{2}^{*}\right.$ and $\mathrm{HCO}^{*}$ dissociation) and species $\left(\mathrm{H}^{*}\right.$ and $\left.\mathrm{CO}^{*}\right)$, can exhibit enormous variability in DRC, depending upon the model parameters. Figure $7 \mathrm{a}-\mathrm{c}$ illustrates this variability in $X_{\mathrm{TRC}}$ for $\mathrm{H}^{*}$ and $X_{\mathrm{RC}}$ for the $\mathrm{CO}_{2}^{*}$ and $\mathrm{HCO}^{*}$ dissociation over the variation in the uncertainty range. If we focus on the DRC for $\mathrm{CO}_{2}^{*}$ dissociation (7b), we observe two broad clusters. For negative values of $\Delta E_{\mathrm{a}}$, the $X_{\mathrm{RC}}$ tend to be clustered around 0 (because a low barrier leads to a higher rate), and for positive values of $\Delta E_{\mathrm{a}}$, the $X_{\mathrm{RC}}$ tend to be clustered around 1 . However, in both cases, there is considerable scatter. Moreover, the feasible set (represented by the red squares) spans the entire horizontal range, with no clearly discernible trend. The results for $\mathrm{HCO}^{*}$ dissociation $(7 \mathrm{c})$, in contrast, show more structure. The results from the feasible set are all tightly clustered around $-0.6<\Delta E_{\mathrm{a}}<-0.2$, which result in $X_{\mathrm{RC}}=0$. When the activation energy for this reaction is increased, the reaction shifts from $X_{\mathrm{RC}} \approx 0$ to $X_{\mathrm{RC}} \approx 1$ and it becomes the RDS. Another clear trend is obtained for the thermodynamic DRC for $\mathrm{H}^{*}$ (Figure $7 \mathrm{a}$ ); as $\mathrm{H}^{*}$ is stabilized on the surface, it has an increasingly inhibiting effect.

By combining these results with the joint sensitivity coefficients from Figure $5 b$, we can begin to see what other parameters contribute the most to the scatter in Figure $7 \mathrm{a}-\mathrm{c}$. Specifically, for both reactions, the parameter with the highest joint sensitivity coefficient is $\delta E_{\mathrm{Pt}}^{\mathrm{HX}}$ (and therefore the heat of formation for $\left.\mathrm{H}^{*}\right)$. Variation in $X_{\mathrm{TRC}}$ for $\mathrm{H}^{*}$ in Figure $7 \mathrm{~d}$ is mostly vertical; it goes from 0 to -2 as $\delta E_{\mathrm{Pt}}^{\mathrm{HX}}$ is decreased (and thus $\mathrm{H}^{*}$ is made more stable), but $\delta E_{\mathrm{Pt}}^{\mathrm{OX}}$ has very little effect. The surface is covered in $\mathrm{H}^{*}$ under these conditions (see Figure S33), which agrees with observations that $X_{\text {TRC }}$ is linked directly to surface coverage. ${ }^{62,108}$ Figure 7 e,f present heatmaps for $X_{\mathrm{RC}}$ of $\mathrm{CO}_{2}^{*}$ and $\mathrm{HCO}^{*}$ dissociation, respectively. In Figure $7 \mathrm{e}$, the values of $X_{\mathrm{RC}} \approx 1$ are generally clustered between -0.3 $<\delta E_{\mathrm{Pt}}^{\mathrm{HX}}<-0.1$, suggesting that $\mathrm{CO}_{2}^{*}$ dissociation is only rate controlling when $\mathrm{H}^{*}$ is stabilized on the surface. At these conditions the surface is covered in $\mathrm{H}^{*}$ and lacks $\mathrm{CO}^{*}$, which is why the production of $\mathrm{CO}^{*}$ via $\mathrm{CO}_{2}^{*}$ dissociation is ratecontrolling. However, the $\mathrm{HCO}^{*}$ dissociation is rate controlling over the entire uncertainty range of $\delta E_{\mathrm{Pt}}^{\mathrm{HX}}$ (Figure $7 \mathrm{f}$ ). Figure $7 \mathrm{~d}$-f clearly indicate that the DRC can change from insensitive to rate controlling within the range of a few $\mathrm{meV}$. 
Figure $7 \mathrm{~g}$-i present heatmaps for $\mathrm{CH}_{4}$ mole fraction as a function of $\delta E_{\mathrm{Pt}}^{\mathrm{OX}}$ as well as the barrier for $\mathrm{CO}_{2}^{*}$ and $\mathrm{HCO}^{*}$ dissociation in combination with $\delta E_{\mathrm{Pt}}^{\mathrm{HX}}$. Other key parameters are reported in the SI. In Figure $7 \mathrm{~h}$ for $\mathrm{CO}_{2}^{*}$ dissociation, we can see a vertical area where $\mathrm{CH}_{4}$ formation is feasible, which is when $\mathrm{H}^{*}$ is destabilized, without a clear dependence on the activation barrier. Figure $7 \mathrm{i}$ shows that $\mathrm{CH}_{4}$ is only produced when $\mathrm{H}^{*}$ is destabilized and the barrier for $\mathrm{HCO}^{*}$ dissociation decreased. When the activation barrier for the $\mathrm{HCO}^{*}$ dissociation is increased, no further conversion pathways for $\mathrm{CO}^{*}$ are available, and the surface will be poisoned by $\mathrm{CO}^{*}$, thereby inhibiting $\mathrm{H}^{*}$ adsorption. Since the activation barrier is determined from the BEP, these points coincide with the pattern for the $\mathrm{O}^{*} / \mathrm{H}^{*}$ dependence (see Figure $7 \mathrm{~g}$ ). A decrease in $\mathrm{O}^{*}$ heat of formation lowers the heat of reaction and thus the activation barrier. Looking at the scatter plot (Figure 7c), we can now state that $\mathrm{HCO}^{*}$ dissociation is never rate-controlling when $\mathrm{CH}_{4}$ is formed, which is why it has also a small DRC for the best cases, and other reactions are rate controlling instead, e.g. $\mathrm{CO}_{2}^{*}$ dissociation for the best match (see Figure 6a). These results highlight a severe limitation of the DRC analysis given the large uncertainty of DFT parameters. This does not question the accuracy or meaning of the DRC concept. It simply shows that the factors which control the methanation activity locally (determined with DRC) are not the same as the global properties that truly determine the methanation activity. The global uncertainty assessment indicates that the $\mathrm{HCO}^{*}$ dissociation in combination with $\mathrm{H}^{*}$ and $\mathrm{O}^{*}$ binding energy are the true factors that control the methanation activity of the $\mathrm{Ni}(111)$ facet. This can also be seen in Figure $3 c-d$, where these three parameters show a clear grouping of values for the feasible set of parameters that agree well with the experimental data. It indicates that these parameters need to be in a certain range to predict the experiments. The modeling results show that only when $\mathrm{H}^{*}$ is destabilized can other important intermediates (e.g., CO*, $\left.\mathrm{O}^{*}\right)$ cover the surface and the destabilization decreases several activation barriers. A high $\mathrm{CO}^{*}$ and $\mathrm{O}^{*}$ coverage favor $\mathrm{CH}_{4}$ production; the $\mathrm{H}^{*}$ surface site fraction for the best cases are actually rather small (see Figure S19). Furthermore, we have seen that all steps with high DRC values are part of the reduced methanation mechanism. Based on our insights gained from the global sensitivity analysis and the global uncertainty of the DRC, we can further hypothesize that the reduced microkinetic model (see Figure $3 \mathrm{~b}$ and Table S10) comprises all the relevant steps and species that determine the methanation activity over the entire uncertainty range, making it the most likely methanation mechanism for the $\mathrm{Ni}(111)$ facet.

Finally, we wish to emphasize that the purpose of this analysis is not to provide a definitive mechanism for $\mathrm{CO}_{2}$ methanation on Ni. In fact, it is difficult to state conclusively whether or not $\mathrm{Ni}(111)$ is the active facet. This is neither a flaw in this study, nor the applied methods, nor automated mechanism generation in general. Since all assumptions on the uncertainty in this study represent only the accuracy of present DFT functionals, ${ }^{32,50-54}$ it indicates that it is not possible for a pure DFT study to conclusively determine the activity of the $\mathrm{Ni}(111)$ facet either. This is evidenced by Lozano-Reis et al. ${ }^{12}$ and Vogt et al., ${ }^{10}$ who reach completely opposite conclusions while the only difference is the applied DFT functional. Moreover, this result is not unique to methanation; a large variation in activity was also observed by Sutton et al. ${ }^{52,58}$ for ethanol steam reforming or Döpking et al..$^{50}$ for the oxygen evolution reaction when uncertainty is considered. However, with the automated mechanism generation, we were able to derive a complete and unbiased mechanism including all the possible chemistry as well as to unravel the reactions and parameters that control the activity over the entire uncertainty range (see Figure 3, 6 and 7), which cannot be done with typical DFT studies.

Feasible sets of microkinetic mechanisms exist within the uncertainty range that agree with the experimental data with remarkable predictive power, but self-consistent sets of parameters can yield virtually every conceivable outcome within this confined uncertainty space of $\pm 0.3 \mathrm{eV}$. Since the experiments can be well described, $\mathrm{Ni}(111)$ could be considered as the active site, but we are aware that this comparison is not entirely fair due to the nature of the supported $\mathrm{Ni}$ catalyst. The $\mathrm{Ni}$ crystals on the supported catalysts are multifaceted, containing the $\mathrm{Ni}(211), \mathrm{Ni}(100)$, and $\mathrm{Ni}(110)$ facet to varying extents ${ }^{8}$ and all can contribute to the methanation activity. ${ }^{10}$ Ultimately, it will be necessary to repeat the outlined procedure for all four $\mathrm{Ni}$ facets independently and combine them in a multifaceted model, as has been done in previous work by some of the authors to describe TPD experiments from a supported Ni catalyst. ${ }^{8}$ Such an effort should address both structural and parametric uncertainty. ${ }^{49}$ The most obvious structural uncertainty would be coverage effects, and future work should include a systematic approach to deal with lateral interactions. Parametric uncertainty, in contrast, should be refined with experimental results when applicable ${ }^{32}$ or with more advanced electronic structure methods where possible, (e.g., hybrid DFT methods $\left.{ }^{110}\right)$. Similarly, the uncertainty correlation in the species energies should be more accurately quantified than the approximate uniform distribution for a more sophisticated error propagation, ${ }^{52,57}$ which can be done by using the BEEF$\mathrm{vdW}$ functional ${ }^{85}$ (see SI for further discussion). Another challenge for mechanism generation and microkinetic modeling for $\mathrm{CO}_{2}$ methanation on industrial catalysts is the influence of basic sites on the support for e.g. $\mathrm{Ni} / \gamma-\mathrm{Al}_{2} \mathrm{O}_{3}$ catalysts. ${ }^{8,75,112}$ Basic supports lead to more active $\mathrm{Ni}$ catalysts because the support participates in the activation of $\mathrm{CO}_{2}$ by providing lower energy pathways at the metal/support interface $^{16,17}$ and should, therefore, be included for these systems.

The combination of linear scaling and BEP relations is commonly used to screen the activity of catalysts over the whole range of transition metals with an assumed microkinetic model, including $\mathrm{CO}^{*}$ methanation. ${ }^{37,38,106,113}$ For the screening procedure, the binding energy of the descriptor species is changed by a few $\mathrm{eV}$ to move across the various transition metals. Simultaneously, the structure of the underlying microkinetic model is assumed to be static, is often derived from the knowledge for one particular metal/facet, and a single pathway is assumed. ${ }^{28,29,37}$ Wolcott et al. ${ }^{108}$ screened catalysts with the DRC method and observed that the rate-controlling transition state is constant in the range of a few $\mathrm{eV}$. In this study, we showed that within a few $\mathrm{meV}$ (i) the mechanism changes significantly, (ii) the activity varies over several orders of magnitude, (iii) the DRC is far from constant, and (iv) global and local rate-controlling parameters are completely different. Consequently, the conclusions drawn from the screening for the most active materials might be incorrect because of the simplified microkinetics. Nonetheless, the usage 
of these screening techniques has boosted catalyst development and advanced our understanding of several important reactions. Including automated mechanism generation into the catalyst screening procedure with correlated uncertainties is not only beneficial, but rather necessary to discover the whole reaction network for each possible metal or alloy and to truly advance the predictive power of the LS and BEP relations in determining the most active and selective materials. ${ }^{34}$ To test our hypothesis we generated an ensemble of 500 distinct mechanism for the $\mathrm{Pt}(111)$ surface and all of these simulations show that $\mathrm{Pt}(111)$ is inactive for the methanation in agreement with the literature ${ }^{37,114}$ (see Figure S37 for further discussion). Although the purpose of this work is emphatically not catalyst screening, the results suggest that a nickel-like alloy that has a slightly reduced binding energy for $\mathrm{H}^{*}$ and slightly increased binding energy for adsorbates that bind through oxygen, relative to $\mathrm{Ni}(111)$, will offer superior production rates for $\mathrm{CH}_{4}$.

Finally, it is worth emphasizing the computational efficiency of this approach. It took approximately 24 CPU-hours to generate all 5,000 mechanisms. The various sensitivity analyses took an additional $\sim 300$ CPU-hours. A single CINEB calculation, in contrast, required approximately 1,300 CPUhours on the same architecture. In other words, the current approach built and analyzed 5,000 mechanisms in one-fifth of the time required to perform a single transition state calculation.

\section{CONCLUSION}

The present work presents the first application of automatic mechanism generation for $\mathrm{CO}_{2}$ hydrogenation to $\mathrm{CH}_{4}$ on $\mathrm{Ni}(111)$ using the open-source automated reaction generation software RMG. ${ }^{4,44,47,48}$ Uncertainties in the DFT-based model generating parameters, such as adsorbate binding energies and activation energies, were explored in a systematic manner that is consistent with the underlying correlation using linear scaling and BEP relations. Moreover, this is the first work including correlated parametric uncertainty in a ratebased automated mechanism generation procedure. RMG was capable of discovering a vast reaction network including up to $\mathrm{C}_{6}$ chemistry, but the main path is the methanation of $\mathrm{CO}_{2}$ via various routes. The global uncertainty analysis reveals that it is necessary to consider the uncertainties in the model input parameters to discover all possible species and reactions.

$\mathrm{CO}_{2}$ methanation simulations with all discovered mechanisms in a PFR model show a vast spread of results, allowing various interpretations of the activity of $\mathrm{Ni}(111)$ within the uncertainty of DFT functionals. It is even possible to reach opposite conclusions consistent with literature DFT studies. In the correlated uncertainty space, there are also feasible sets of parameters that describe our experimental results from $\mathrm{Ni}$ / $\mathrm{SiO}_{2}$ catalyst with a remarkable accuracy without parameter optimization, further contrasting the role of $\mathrm{Ni}(111)$ as the active site. In combination with the global sensitivity analysis, it was possible to determine which factors control the activity of $\mathrm{Ni}(111)$ and to derive a most likely methanation mechanism, which is a combination of the redox and carboxyl pathway. The only relevant conversion from $\mathrm{CO} *$ to $\mathrm{CH}_{4}$ occurs via $\mathrm{HCO}^{*}$, and this reaction together with the thermochemistry of $\mathrm{H}^{*}$ and $\mathrm{O}^{*}$ determines the (in)activity of $\mathrm{Ni}(111)$.

The analysis reveals that results from the degree of rate control approach are highly sensitive to the model uncertainty and that small changes to the parameters can result in completely different RDS or rate-controlling intermediates. A more useful approach is to perform the degree of rate control analysis over the entire uncertainty range, since it quantifies which factors truly control the activity. Therefore, the method provides a hierarchy for parameter refinement with experimental results or more accurate, though likewise more expensive, DFT methods that can ultimately be fed back to RMG and gradually improve the software. Steady-state and transient $\mathrm{CO}_{2}$ methanation experiments are currently being conducted in a Berty-type reactor to investigate the $\mathrm{CO}_{2}$ methanation at varying compositions and higher pressures, which will provide a database for the future refinement of the microkinetic model. This new methodology is computationally efficient and can be applied to arbitrary systems in heterogeneous catalysis.

\section{ASSOCIATED CONTENT \\ Supporting Information}

The Supporting Information is available free of charge at https://pubs.acs.org/doi/10.1021/jacsau.1c00276.

Detailed information on the theoretical methods; DFT/ CINEB results; additional simulation results; DRC and concentration heatmaps; DRC scatter plots; microkinetic model of the best case (PDF)

\section{AUTHOR INFORMATION}

Corresponding Authors

Bjarne Kreitz - Institute of Chemical and Electrochemical Process Engineering, Clausthal University of Technology, Clausthal-Zellerfeld 38678, Germany; School of Engineering, Brown University, Providence, Rhode Island 02912, United States; 이이.org/0000-0003-0158-9147; Phone: +49 532372 2473; Email: kreitz@icvt.tu-clausthal.de

C. Franklin Goldsmith - School of Engineering, Brown University, Providence, Rhode Island 02912, United States; () orcid.org/0000-0002-2212-0172; Phone: +1 401863 6468; Email: franklin_goldsmith@brown.edu

\section{Authors}

Khachik Sargsyan - Sandia National Laboratories, Livermore, California 94550, United States

Katrín Blöndal - School of Engineering, Brown University, Providence, Rhode Island 02912, United States; (1) orcid.org/0000-0002-0964-8589

Emily J. Mazeau - Department of Chemical Engineering, Northeastern University, Boston, Massachusetts 02115, United States; 이이.org/0000-0001-8844-9563

Richard H. West - Department of Chemical Engineering, Northeastern University, Boston, Massachusetts 02115,

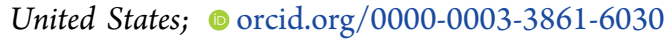

Gregor D. Wehinger - Institute of Chemical and Electrochemical Process Engineering, Clausthal University of Technology, Clausthal-Zellerfeld 38678, Germany; (1) orcid.org/0000-0002-1774-3391

Thomas Turek - Institute of Chemical and Electrochemical Process Engineering, Clausthal University of Technology, Clausthal-Zellerfeld 38678, Germany; (1) orcid.org/00000002-7415-1966

Complete contact information is available at: https://pubs.acs.org/10.1021/jacsau.1c00276 


\section{Notes}

The authors declare no competing financial interest.

\section{ACKNOWLEDGMENTS}

B.K. gratefully acknowledges financial support from the NaWuReT (ProcessNet, DECHEMA) for a virtual research collaboration with CFG in the fall of 2020. B.K. and T.T. acknowledge financial support from the Deutsche Forschungsgemeinschaft (DFG, German Research Foundation), project no. 290019031. K.S., E.M., K.B., R.H.W., and C.F.G. gratefully acknowledge support by the U.S. Department of Energy, Office of Science, Basic Energy Sciences, under Award No. 0000232253, as part of the Computational Chemical Sciences Program. B.K. and C.F.G. thank Habib Najm and Judit Zádor for helpful discussions on sensitivity analysis. Sandia National Laboratories is a multimission laboratory managed and operated by National Technology and Engineering Solutions of Sandia, LLC, a wholly owned subsidiary of Honeywell International Inc., for the U.S. Department of Energy's National Nuclear Security Administration under contract DE-NA0003525.

\section{REFERENCES}

(1) Götz, M.; Lefebvre, J.; Mörs, F.; McDaniel Koch, A.; Graf, F.; Bajohr, S.; Reimert, R.; Kolb, T. Renewable Power-to-Gas: A Technological and Economic Review. Renewable Energy 2016, 85, 1371-1390.

(2) Vogt, C.; Monai, M.; Kramer, G. J.; Weckhuysen, B. M. The Renaissance of the Sabatier Reaction and its Applications on Earth and in Space. Nat. Catal. 2019, 2, 188-197.

(3) Kalz, K. F.; Kraehnert, R.; Dvoyashkin, M.; Dittmeyer, R.; Gläser, R.; Krewer, U.; Reuter, K.; Grunwaldt, J.-D. Future Challenges in Heterogeneous Catalysis: Understanding Catalysts under Dynamic Reaction Conditions. ChemCatChem 2017, 9, 17-29.

(4) Kreitz, B.; Wehinger, G. D.; Turek, T. Dynamic Simulation of the $\mathrm{CO}_{2}$ Methanation in a Micro-Structured Fixed-Bed Reactor. Chem. Eng. Sci. 2019, 195, 541-552.

(5) Fischer, K. L.; Langer, M. R.; Freund, H. Dynamic Carbon Dioxide Methanation in a Wall-Cooled Fixed Bed Reactor: Comparative Evaluation of Reactor Models. Ind. Eng. Chem. Res. 2019, 58, 19406-19420.

(6) Kreitz, B.; Brauns, J.; Wehinger, G. D.; Turek, T. Modeling the Dynamic Power-to-Gas Process: Coupling Electrolysis with $\mathrm{CO}_{2}$ Methanation. Chem. Ing. Tech. 2020, 92, 1992-1997.

(7) Gao, J.; Liu, Q.; Gu, F.; Liu, B.; Zhong, Z.; Su, F. Recent Advances in Methanation Catalysts for the Production of Synthetic Natural Gas. RSC Adv. 2015, 5, 22759-22776.

(8) Kreitz, B.; Wehinger, G. D.; Goldsmith, C. F.; Turek, T. Microkinetic Modeling of the $\mathrm{CO}_{2}$ Desorption from Supported Multifaceted Ni Catalysts. J. Phys. Chem. C 2021, 125, 2984-3000.

(9) Vogt, C.; Groeneveld, E.; Kamsma, G.; Nachtegaal, M.; Lu, L.; Kiely, C. J.; Berben, P. H.; Meirer, F.; Weckhuysen, B. M. Unravelling Structure Sensitivity in $\mathrm{CO}_{2}$ Hydrogenation over Nickel. Nat. Catal. 2018, 1, 127-134.

(10) Vogt, C.; Monai, M.; Sterk, E. B.; Palle, J.; Melcherts, A. E. M.; Zijlstra, B.; Groeneveld, E.; Berben, P. H.; Boereboom, J. M.; Hensen, E. J. M.; Meirer, F.; Filot, I. A. W.; Weckhuysen, B. M. Understanding Carbon Dioxide Activation and Carbon-Carbon Coupling over Nickel. Nat. Commun. 2019, 10, 5330.

(11) Beierlein, D.; Häussermann, D.; Pfeifer, M.; Schwarz, T.; Stöwe, K.; Traa, Y.; Klemm, E. Is the $\mathrm{CO}_{2}$ Methanation on Highly Loaded Ni- $\mathrm{Al}_{2} \mathrm{O}_{3}$ Catalysts Really Structure-Sensitive? Appl. Catal., B 2019, 247, 200-219.

(12) Lozano-Reis, P.; Prats, H.; Gamallo, P.; Illas, F.; Sayós, R. Multiscale Study of the Mechanism of Catalytic $\mathrm{CO}_{2}$ Hydrogenation: Role of the Ni(111) Facets. ACS Catal. 2020, 10, 8077-8089.
(13) Heine, C.; Lechner, B. A. J.; Bluhm, H.; Salmeron, M. Recycling of $\mathrm{CO}_{2}$ : Probing the Chemical State of the $\mathrm{Ni}(111)$ Surface during the Methanation Reaction with Ambient-Pressure X-Ray Photoelectron Spectroscopy. J. Am. Chem. Soc. 2016, 138, 1324613252.

(14) Ren, J.; Guo, H.; Yang, J.; Qin, Z.; Lin, J.; Li, Z. Insights Into the Mechanisms of $\mathrm{CO}_{2}$ Methanation on $\mathrm{Ni}(111)$ Surfaces by Density Functional Theory. Appl. Surf. Sci. 2015, 351, 504-516.

(15) Zhou, M.; Liu, B. DFT Investigation on the Competition of the Water-Gas Shift Reaction Versus Methanation on Clean and Potassium-Modified Nickel(111) Surfaces. ChemCatChem 2015, 7, 3928-3935.

(16) Foppa, L.; Margossian, T.; Kim, S. M.; Müller, C.; Copéret, C.; Larmier, K.; Comas-Vives, A. Contrasting the Role of $\mathrm{Ni} / \mathrm{Al}_{2} \mathrm{O}_{3}$ Interfaces in Water-Gas Shift and Dry Reforming of Methane. J. Am. Chem. Soc. 2017, 139, 17128-17139.

(17) Silaghi, M.-C.; Comas-Vives, A.; Copéret, C. $\mathrm{CO}_{2}$ Activation on $\mathrm{Ni} / \gamma-\mathrm{Al}_{2} \mathrm{O}_{3}$ Catalysts by First-Principles Calculations: From Ideal Surfaces to Supported Nanoparticles. ACS Catal. 2016, 6, 45014505.

(18) Andersson, M. P.; Abild-Pedersen, F.; Remediakis, I. N.; Bligaard, T.; Jones, G.; Engbæk, J.; Lytken, O.; Horch, S.; Nielsen, J. H.; Sehested, J. Structure Sensitivity of the Methanation Reaction: $\mathrm{H}_{2}$-Induced CO Dissociation on Nickel Surfaces. J. Catal. 2008, 255, 6-19.

(19) Catapan, R. C.; Oliveira, A. A. M.; Chen, Y.; Vlachos, D. G. DFT Study of the Water-Gas Shift Reaction and Coke Formation on $\mathrm{Ni}(111)$ and $\mathrm{Ni}(211)$ Surfaces. J. Phys. Chem. C 2012, 116, 2028120291.

(20) de Carvalho, T. P.; Catapan, R. C.; Oliveira, A. A. M.; Vlachos, D. G. Microkinetic Modeling and Reduced Rate Expression of the Water-Gas Shift Reaction on Nickel. Ind. Eng. Chem. Res. 2018, 57, 10269-10280.

(21) Zhang, M.; Zijlstra, B.; Filot, I. A. W.; Li, F.; Wang, H.; Li, J.; Hensen, E. J. M. A Theoretical Study of the Reverse Water-Gas Shift Reaction on $\mathrm{Ni}(111)$ and $\mathrm{Ni}(311)$ Surfaces. Can. J. Chem. Eng. 2020, 98, 740-748.

(22) Maulana, A. L.; Putra, R. I. D.; Saputro, A. G.; Agusta, M. K.; Nugraha; Dipojono, H. K. DFT and Microkinetic Investigation of Methanol Synthesis via $\mathrm{CO}_{2}$ Hydrogenation on $\mathrm{Ni}(111)$-Based Surfaces. Phys. Chem. Chem. Phys. 2019, 21, 20276-20286.

(23) Peng, G.; Sibener, S. J.; Schatz, G. C.; Ceyer, S. T.; Mavrikakis, M. $\mathrm{CO}_{2}$ Hydrogenation to Formic Acid on $\mathrm{Ni}(111)$. J. Phys. Chem. C 2012, 116, 3001-3006.

(24) Banerjee, A.; Navarro, V.; Frenken, J. W. M.; van Bavel, A. P.; Kuipers, H. P. C. E.; Saeys, M. Shape and Size of Cobalt Nanoislands Formed Spontaneously on Cobalt Terraces during Fischer-Tropsch Synthesis. J. Phys. Chem. Lett. 2016, 7, 1996-2001.

(25) Weststrate, C. J. K.-J.; Sharma, D.; Garcia Rodriguez, D.; Gleeson, M. A.; Fredriksson, H. O. A.; Niemantsverdriet, J. W. H. Mechanistic Insight Into Carbon-Carbon Bond Formation on Cobalt Under Simulated Fischer-Tropsch Synthesis Conditions. Nat. Commun. 2020, 11, 750.

(26) Grabow, L. C.; Mavrikakis, M. Mechanism of Methanol Synthesis on $\mathrm{Cu}$ through $\mathrm{CO}_{2}$ and $\mathrm{CO}$ Hydrogenation. ACS Catal. 2011, 1, 365-384.

(27) Gunasooriya, G. T. K. K.; van Bavel, A. P.; Kuipers, H. P. C. E.; Saeys, M. Key Role of Surface Hydroxyl Groups in C-O Activation during Fischer-Tropsch Synthesis. ACS Catal. 2016, 6, 3660-3664.

(28) Studt, F.; Abild-Pedersen, F.; Wu, Q.; Jensen, A. D.; Temel, B.; Grunwaldt, J.-D.; Nørskov, J. K. CO Hydrogenation to Methanol on Cu-Ni Catalysts: Theory and Experiment. J. Catal. 2012, 293, 51-60.

(29) Studt, F.; Sharafutdinov, I.; Abild-Pedersen, F.; Elkjær, C. F.; Hummelshøj, J. S.; Dahl, S.; Chorkendorff, I.; Nørskov, J. K. Discovery of a Ni-Ga catalyst for Carbon Dioxide Reduction to Methanol. Nat. Chem. 2014, 6, 320-324.

(30) Demir, B.; Kropp, T.; Gilcher, E. B.; Mavrikakis, M.; Dumesic, J. A. Effects of Water on the Kinetics of Acetone Hydrogenation over Pt and Ru Catalysts. J. Catal. 2021, 279, 337. 
(31) Bhandari, S.; Rangarajan, S.; Maravelias, C. T.; Dumesic, J. A.; Mavrikakis, M. Reaction Mechanism of Vapor-Phase Formic Acid Decomposition over Platinum Catalysts: DFT, Reaction Kinetics Experiments, and Microkinetic Modeling. ACS Catal. 2020, 10, $4112-4126$.

(32) Bhandari, S.; Rangarajan, S.; Mavrikakis, M. Combining Computational Modeling with Reaction Kinetics Experiments for Elucidating the In Situ Nature of the Active Site in Catalysis. Acc. Chem. Res. 2020, 53, 1893-1904.

(33) Margraf, J. T.; Reuter, K. Systematic Enumeration of Elementary Reaction Steps in Surface Catalysis. ACS Omega 2019, 4, 3370-3379.

(34) Bruix, A.; Margraf, J. T.; Andersen, M.; Reuter, K. FirstPrinciples-Based Multiscale Modelling of Heterogeneous Catalysis. Nat. Catal. 2019, 2, 659-670.

(35) Abild-Pedersen, F.; Greeley, J.; Studt, F.; Rossmeisl, J.; Munter, T. R.; Moses, P. G.; Skúlason, E.; Bligaard, T.; Nørskov, J. K. Scaling Properties of Adsorption Energies for Hydrogen-Containing Molecules on Transition-Metal Surfaces. Phys. Rev. Lett. 2007, 99, 016105.

(36) Sutton, J. E.; Vlachos, D. G. Building Large Microkinetic Models With First-Principles' Accuracy at Reduced Computational Cost. Chem. Eng. Sci. 2015, 121, 190-199.

(37) Nørskov, J. K.; Bligaard, T.; Rossmeisl, J.; Christensen, C. H. Towards the Computational Design of Solid Catalysts. Nat. Chem. 2009, 1, 37-46.

(38) Nørskov, J. K.; Abild-Pedersen, F.; Studt, F.; Bligaard, T. Density Functional Theory in Surface Chemistry and Catalysis. Proc. Natl. Acad. Sci. U. S. A. 2011, 108, 937-943.

(39) Vernuccio, S.; Broadbelt, L. J. Discerning complex reaction networks using automated generators. AIChE J. 2019, 65, 17.

(40) Rangarajan, S.; Bhan, A.; Daoutidis, P. Identification and Analysis of Synthesis Routes in Complex Catalytic Reaction Networks for Biomass Upgrading. Appl. Catal., B 2014, 145, 149-160.

(41) Rangarajan, S.; Brydon, R. R. O.; Bhan, A.; Daoutidis, P. Automated Identification of Energetically Feasible Mechanisms of Complex Reaction Networks in Heterogeneous Catalysis: Application to Glycerol Conversion on Transition Metals. Green Chem. 2014, 16, 813-823.

(42) Zhang, S.; Broadbelt, L. J.; Androulakis, I. P.; Ierapetritou, M. G. Reactive Flow Simulation Based on the Integration of Automated Mechanism Generation and On-the-Fly Reduction. Energy Fuels 2014, 28, 4801-4811.

(43) Gao, C. W.; Allen, J. W.; Green, W. H.; West, R. H. Reaction Mechanism Generator: Automatic Construction of Chemical Kinetic Mechanisms. Comput. Phys. Commun. 2016, 203, 212-225.

(44) Goldsmith, C. F.; West, R. H. Automatic Generation of Microkinetic Mechanisms for Heterogeneous Catalysis. J. Phys. Chem. C 2017, 121, 9970-9981.

(45) Mazeau, E. J.; Satpute, P.; Blöndal, K.; Goldsmith, C. F.; West, R. H. Automated Mechanism Generation Using Linear Scaling Relationships and Sensitivity Analyses Applied to Catalytic Partial Oxidation of Methane. ACS Catal. 2021, 11, 7114-7125.

(46) Blondal, K.; Jelic, J.; Mazeau, E.; Studt, F.; West, R. H.; Goldsmith, C. F. Computer-Generated Kinetics for Coupled Heterogeneous/Homogeneous Systems: A Case Study in Catalytic Combustion of Methane on Platinum. Ind. Eng. Chem. Res. 2019, 58, 17682-17691.

(47) Liu, M.; Grinberg Dana, A.; Johnson, M. S.; Goldman, M. J.; Jocher, A.; Payne, A. M.; Grambow, C. A.; Han, K.; Yee, N. W.; Mazeau, E. J.; Blondal, K.; West, R. H.; Goldsmith, C. F.; Green, W. H. Reaction Mechanism Generator v3.0: Advances in Automatic Mechanism Generation. J. Chem. Inf. Model. 2021, 61, 2686.

(48) Green, W. H.; West, R. H. RMG - Reaction Mechanism Generator. https://rmg.mit.edu/, 2021; Version 3.0.

(49) Wang, H.; Sheen, D. A. Combustion kinetic model uncertainty quantification, propagation and minimization. Prog. Energy Combust. Sci. 2015, 47, 1-31.

(50) Döpking, S.; Plaisance, C. P.; Strobusch, D.; Reuter, K.; Scheurer, C.; Matera, S. Addressing Global Uncertainty and
Sensitivity in First-Principles Based Microkinetic Models by an Adaptive Sparse Grid Approach. J. Chem. Phys. 2018, 148, 034102.

(51) Ulissi, Z. W.; Medford, A. J.; Bligaard, T.; Nørskov, J. K. To Address Surface Reaction Network Complexity Using Scaling Relations Machine Learning and DFT Calculations. Nat. Commun. 2017, 8, 14621.

(52) Sutton, J. E.; Guo, W.; Katsoulakis, M. A.; Vlachos, D. G. Effects of Correlated Parameters and Uncertainty in ElectronicStructure-Based Chemical Kinetic Modelling. Nat. Chem. 2016, 8, 331-337.

(53) Matera, S.; Schneider, W. F.; Heyden, A.; Savara, A. Progress in Accurate Chemical Kinetic Modeling, Simulations, and Parameter Estimation for Heterogeneous Catalysis. ACS Catal. 2019, 9, 66246647.

(54) Studt, F. Grand Challenges in Computational Catalysis. Frontiers in Catalysis 2021, 1, 016105.

(55) Wellendorff, J.; Silbaugh, T. L.; Garcia-Pintos, D.; Nørskov, J. K.; Bligaard, T.; Studt, F.; Campbell, C. T. A Benchmark Database for Adsorption Bond Energies to Transition Metal Surfaces and Comparison to Selected DFT Functionals. Surf. Sci. 2015, 640, 3644.

(56) Bligaard, T.; Nørskov, J. K.; Dahl, S.; Matthiesen, J.; Christensen, C. H.; Sehested, J. The Brønsted-Evans-Polanyi Relation and the Volcano Curve in Heterogeneous Catalysis. J. Catal. 2004, 224, 206-217.

(57) Medford, A. J.; Wellendorff, J.; Vojvodic, A.; Studt, F.; AbildPedersen, F.; Jacobsen, K. W.; Bligaard, T.; Nørskov, J. K. Catalysis. Assessing the Reliability of Calculated Catalytic Ammonia Synthesis Rates. Science 2014, 345, 197-200.

(58) Sutton, J. E.; Vlachos, D. G. Effect of Errors in Linear Scaling Relations and Brønsted-Evans-Polanyi Relations on Activity and Selectivity Maps. J. Catal. 2016, 338, 273-283.

(59) Wang, B.; Chen, S.; Zhang, J.; Li, S.; Yang, B. Propagating DFT Uncertainty to Mechanism Determination, Degree of Rate Control, and Coverage Analysis: The Kinetics of Dry Reforming of Methane. J. Phys. Chem. C 2019, 123, 30389-30397.

(60) Gu, T.; Wang, B.; Chen, S.; Yang, B. Automated Generation and Analysis of the Complex Catalytic Reaction Network of Ethanol Synthesis from Syngas on $\mathrm{Rh}(111)$. ACS Catal. 2020, 10, 6346-6355.

(61) Campbell, C. T. Finding the Rate-Determining Step in a Mechanism. J. Catal. 2001, 204, 520-524.

(62) Stegelmann, C.; Andreasen, A.; Campbell, C. T. Degree of Rate Control: How Much the Energies of Intermediates and Transition States Control Rates. J. Am. Chem. Soc. 2009, 131, 8077-8082.

(63) Susnow, R. G.; Dean, A. M.; Green, W. H.; Peczak, P.; Broadbelt, L. J. Rate-Based Construction of Kinetic Models for Complex Systems. J. Phys. Chem. A 1997, 101, 3731-3740.

(64) Goldsmith, C. F. Estimating the Thermochemistry of Adsorbates Based Upon Gas-Phase Properties. Top. Catal. 2012, 55, 366-375.

(65) Hammer, B.; Hansen, L. B.; Nørskov, J. K. Improved Adsorption Energetics Within Density-Functional Theory Using Revised Perdew-Burke-Ernzerhof Functionals. Phys. Rev. B: Condens. Matter Mater. Phys. 1999, 59, 7413-7421.

(66) Kresse, G.; Furthmüller, J. Efficient Iterative Schemes for ab Initio Total-Energy Calculations Using a Plane-Wave Basis Set. Phys. Rev. B: Condens. Matter Mater. Phys. 1996, 54, 11169-11186.

(67) Kresse, G.; Furthmüller, J. Efficiency of Ab-Initio Total Energy Calculations for Metals and Semiconductors Using a Plane-Wave Basis Set. Comput. Mater. Sci. 1996, 6, 15-50.

(68) Grimme, S. Semiempirical GGA-Type Density Functional Constructed with a Long-Range Dispersion Correction. J. Comput. Chem. 2006, 27, 1787-1799.

(69) Delgado, K.; Maier, L.; Tischer, S.; Zellner, A.; Stotz, H.; Deutschmann, O. Surface Reaction Kinetics of Steam- and $\mathrm{CO}_{2}^{-}$ Reforming as Well as Oxidation of Methane over Nickel-Based Catalysts. Catalysts 2015, 5, 871-904. 
(70) Schmider, D.; Maier, L.; Deutschmann, O. Reaction Kinetics of $\mathrm{CO}$ and $\mathrm{CO}_{2}$ Methanation over Nickel. Ind. Eng. Chem. Res. 2021, 60, 5792.

(71) Wang, S.; Temel, B.; Shen, J.; Jones, G.; Grabow, L. C.; Studt, F.; Bligaard, T.; Abild-Pedersen, F.; Christensen, C. H.; Nørskov, J. K. Universal Brønsted-Evans-Polanyi Relations for C-C, C-O, C-N, N-O, N-N, and O-O Dissociation Reactions. Catal. Lett. 2011, 141, 370373.

(72) Sutton, J. E.; Panagiotopoulou, P.; Verykios, X. E.; Vlachos, D. G. Combined DFT, Microkinetic, and Experimental Study of Ethanol Steam Reforming on Pt. J. Phys. Chem. C 2013, 117, 4691-4706.

(73) Henkelman, G.; Uberuaga, B. P.; Jónsson, H. A Climbing Image Nudged Elastic Band Method for Finding Saddle Points and Minimum Energy Paths. J. Chem. Phys. 2000, 113, 9901-9904.

(74) Kreitz, B.; Martínez Arias, A.; Martin, J.; Weber, A. P.; Turek, T. Spray-Dried Ni Catalysts with Tailored Properties for $\mathrm{CO}_{2}$ Methanation. Catalysts 2020, 10, 1410.

(75) Pan, Q.; Peng, J.; Sun, T.; Wang, S.; Wang, S. Insight Into the Reaction Route of $\mathrm{CO}_{2}$ Methanation: Promotion Effect of Medium Basic Sites. Catal. Commun. 2014, 45, 74-78.

(76) Friedland, J.; Kreitz, B.; Grimm, H.; Turek, T.; Güttel, R. Measuring Adsorption Capacity of Supported Catalysts with a Novel Quasi-Continuous Pulse Chemisorption Method. ChemCatChem 2020, 12, 4373-4386.

(77) Goodwin, D. G.; Speth, R. L.; Moffat, H. K.; Weber, B. W. Cantera: An Object-Oriented Software Toolkit for Chemical Kinetics, Thermodynamics, and Transport Processes, version 2.4.0, 2018; https:// www.cantera.org.

(78) Kreitz, B.; Sargsyan, K.; Mazeau, E. J.; Blöndal, K.; West, R. H.; Wehinger, G. D.; Turek, T.; Goldsmith, C. F. Data for Quantifying the Impact of Parametric Uncertainty on Automatic Mechanism Generation for $\mathrm{CO}_{2}$ Hydrogenation on $\mathrm{Ni}(111), 2021$; DOI: 10.5281/ zenodo.4662851.

(79) Gao, C. W.; Liu, M.; Green, W. H. Uncertainty Analysis of Correlated Parameters in Automated Reaction Mechanism Generation. Int. J. Chem. Kinet. 2020, 52, 266-282.

(80) Ruscic, B.; Pinzon, R. E.; Morton, M. L.; von Laszevski, G.; Bittner, S. J.; Nijsure, S. G.; Amin, K. A.; Minkoff, M.; Wagner, A. F. Introduction to Active Thermochemical Tables: Several "Key" Enthalpies of Formation Revisited. J. Phys. Chem. A 2004, 108, 9979-9997.

(81) Ruscic, B.; Bross, D. H. Active Thermochemical Tables (ATcT) Values Based on ver. $1.122 \mathrm{~g}$ of the Thermochemical Network, https:// atct.anl.gov.

(82) Ulissi, Z.; Prasad, V.; Vlachos, D. G. Effect of Multiscale Model Uncertainty on Identification of Optimal Catalyst Properties. J. Catal. 2011, 281, 339-344.

(83) Medford, A. J.; Lausche, A. C.; Abild-Pedersen, F.; Temel, B.; Schjødt, N. C.; Nørskov, J. K.; Studt, F. Activity and Selectivity Trends in Synthesis Gas Conversion to Higher Alcohols. Top. Catal. 2014, 57, 135-142.

(84) Medford, A. J.; Vojvodic, A.; Hummelshøj, J. S.; Voss, J.; AbildPedersen, F.; Studt, F.; Bligaard, T.; Nilsson, A.; Nørskov, J. K. From the Sabatier Principle to a Predictive Theory of Transition-Metal Heterogeneous Catalysis. J. Catal. 2015, 328, 36-42.

(85) Wellendorff, J.; Lundgaard, K. T.; Møgelhøj, A.; Petzold, V.; Landis, D. D.; Nørskov, J. K.; Bligaard, T.; Jacobsen, K. W. Density Functionals for Surface Science: Exchange-Correlation Model Development with Bayesian Error Estimation. Phys. Rev. B: Condens. Matter Mater. Phys. 2012, 85, 316.

(86) Prager, J.; Najm, H. N.; Sargsyan, K.; Safta, C.; Pitz, W. J. Uncertainty Quantification of Reaction Mechanisms Accounting for Correlations Introduced by Rate Rules and Fitted Arrhenius Parameters. Combust. Flame 2013, 160, 1583-1593.

(87) Sutton, J. E.; Vlachos, D. G. Ethanol Activation on ClosedPacked Surfaces. Ind. Eng. Chem. Res. 2015, 54, 4213-4225.

(88) Sobol', I. On the Distribution of Points in a Cube and the Approximate Evaluation of Integrals. USSR Computational Mathematics and Mathematical Physics 1967, 7, 86-112.
(89) Paszke, A. et al. In Advances in Neural Information Processing Systems 32; Wallach, H., Larochelle, H., Beygelzimer, A., d'single Alché-Buc, F., Fox, E., Garnett, R., Eds.; Curran Associates, Inc., 2019; pp 8024-8035.

(90) Saltelli, A.; Tarantola, S.; Campolongo, F.; Ratto, M. Sensitivity Analysis in Practice: A Guide to Assessing Scientific Models; Wiley Online Library, 2004; Vol. 1.

(91) Debusschere, B.; Najm, H.; Pébay, P.; Knio, O.; Ghanem, R.; Le Maitre, O. Numerical Challenges in the Use of Polynomial Chaos Representations for Stochastic Processes. SIAM J. Sci. Comput. 2004, 26, 698-719.

(92) Debusschere, B.; Sargsyan, K.; Safta, C.; Chowdhary, K. In Handbook of Uncertainty Quantification; Ghanem, R., Higdon, D., Owhadi, H., Eds.; Springer, 2017; pp 1807-1827.

(93) Crestaux, T.; Le Maître, O.; Martinez, J. Polynomial Chaos Expansion for Sensitivity Analysis. Reliab. Eng. Syst. Safety 2009, 94, $1161-1172$.

(94) Turányi, T.; Tomlin, A. S. Analysis of Kinetic Reaction Mechanisms; Springer: Berlin, 2014.

(95) Campbell, C. T. The Degree of Rate Control: A Powerful Tool for Catalysis Research. ACS Catal. 2017, 7, 2770-2779.

(96) Zádor, J.; Zsély, I. G.; Turányi, T.; Ratto, M.; Tarantola, S.; Saltelli, A. Local and Global Uncertainty Analyses of a Methane Flame Model. J. Phys. Chem. A 2005, 109, 9795-9807.

(97) Abelló, S.; Berrueco, C.; Montané, D. High-Loaded NickelAlumina Catalyst for Direct $\mathrm{CO}_{2}$ Hydrogenation Into Synthetic Natural Gas (SNG). Fuel 2013, 113, 598-609.

(98) Koschany, F.; Schlereth, D.; Hinrichsen, O. On the Kinetics of the Methanation of Carbon Dioxide on Coprecipitated $\mathrm{NiAl}(\mathrm{O})_{\mathrm{x}}$. Appl. Catal., B 2016, 181, 504-516.

(99) Aziz, M.; Jalil, A. A.; Triwahyono, S.; Mukti, R. R.; Taufiq-Yap, Y. H.; Sazegar, M. R. Highly Active Ni-promoted Mesostructured Silica Nanoparticles for $\mathrm{CO}_{2}$ Methanation. Appl. Catal., B 2014, 147, 359-368.

(100) Vrijburg, W. L.; van Helden, J. W. A.; van Hoof, A. J. F.; Friedrich, H.; Groeneveld, E.; Pidko, E. A.; Hensen, E. J. M. Tunable Colloidal Ni Nanoparticles Confined and Redistributed in Mesoporous Silica for $\mathrm{CO}_{2}$ Methanation. Catal. Sci. Technol. 2019, 9, $2578-2591$

(101) Mhadeshwar, A. B.; Wang, H.; Vlachos, D. G. Thermodynamic Consistency in Microkinetic Development of Surface Reaction Mechanisms. J. Phys. Chem. B 2003, 107, 12721-12733.

(102) Salciccioli, M.; Stamatakis, M.; Caratzoulas, S.; Vlachos, D. G. A Review of Multiscale Modeling of Metal-Catalyzed Reactions: Mechanism Development for Complexity and Emergent Behavior. Chem. Eng. Sci. 2011, 66, 4319-4355.

(103) Vesselli, E.; Rizzi, M.; de Rogatis, L.; Ding, X.; Baraldi, A.; Comelli, G.; Savio, L.; Vattuone, L.; Rocca, M.; Fornasiero, P.; Baldereschi, A.; Peressi, M. Hydrogen-Assisted Transformation of $\mathrm{CO}_{2}$ on Nickel: The Role of Formate and Carbon Monoxide. J. Phys. Chem. Lett. 2010, 1, 402-406.

(104) Galhardo, T. S.; Braga, A. H.; Arpini, B. H.; Szanyi, J.; Gonçalves, R. V.; Zornio, B. F.; Miranda, C. R.; Rossi, L. M. Optimizing Active Sites for High CO Selectivity during $\mathrm{CO}_{2}$ Hydrogenation over Supported Nickel Catalysts. J. Am. Chem. Soc. 2021, 143, 4268-4280.

(105) Ferrin, P.; Simonetti, D.; Kandoi, S.; Kunkes, E.; Dumesic, J. A.; Nørskov, J. K.; Mavrikakis, M. Modeling Ethanol Decomposition on Transition Metals: A Combined Application of Scaling and Brønsted-Evans-Polanyi Relations. J. Am. Chem. Soc. 2009, 131, 5809-5815.

(106) Lausche, A. C.; Medford, A. J.; Khan, T. S.; Xu, Y.; Bligaard, T.; Abild-Pedersen, F.; Nørskov, J. K.; Studt, F. On the Effect of Coverage-Dependent Adsorbate-Adsorbate Interactions for $\mathrm{CO}$ Methanation on Transition Metal Surfaces. J. Catal. 2013, 307, 275-282.

(107) Grabow, L. C.; Hvolbæk, B.; Nørskov, J. K. Understanding Trends in Catalytic Activity: The Effect of Adsorbate-Adsorbate 
Interactions for CO Oxidation Over Transition Metals. Top. Catal. 2010, 53, 298-310.

(108) Wolcott, C. A.; Medford, A. J.; Studt, F.; Campbell, C. T. Degree of Rate Control Approach to Computational Catalyst Screening. J. Catal. 2015, 330, 197-207.

(109) Mao, Z.; Campbell, C. T. The Degree of Rate Control of Catalyst-Bound Intermediates in Catalytic Reaction Mechanisms: Relationship to Site Coverage. J. Catal. 2020, 381, 53-62.

(110) Sauer, J. Ab Initio Calculations for Molecule-Surface Interactions with Chemical Accuracy. Acc. Chem. Res. 2019, 52, 3502-3510.

(111) Brown, W. A.; Kose, R.; King, D. A. Femtomole Adsorption Calorimetry on Single-Crystal Surfaces. Chem. Rev. 1998, 98, 797832.

(112) Ewald, S.; Hinrichsen, O. On the Interaction of $\mathrm{CO}_{2}$ with NiAl Catalysts. Appl. Catal., A 2019, 580, 71-80.

(113) Jones, G.; Bligaard, T.; Abild-Pedersen, F.; Nørskov, J. K. Using Scaling Relations to Understand Trends in the Catalytic Activity of Transition Metals. J. Phys.: Condens. Matter 2008, 20, 064239.

(114) Andersson, M.; Bligaard, T.; Kustov, A.; Larsen, K.; Greeley, J.; Johannessen, T.; Christensen, C.; Nørskov, J. Toward Computational Screening in Heterogeneous Catalysis: Pareto-Optimal Methanation Catalysts. J. Catal. 2006, 239, 501-506. 